\title{
molecules
}

ISSN 1420-3049

(C) 2008 by MDPI

www.mdpi.org/molecules

Review

\section{Prodrugs for Amines}

Ana L. Simplício ${ }^{1,2, *}$, John M. Clancy ${ }^{3}$ and John F. Gilmer ${ }^{3}$

${ }^{1}$ Instituto de Tecnologia Química e Biológica, Universidade Nova de Lisboa, Av. da República EAN, 2780-157 Oeiras, Portugal

2 IBET, Apartado 12, 2781-901 Oeiras, Portugal

${ }^{3}$ School of Pharmacy, Trinity College, Dublin 2, Ireland; E-mails: jclancy@tcd.ie; gilmerjf@tcd.ie

* Author to whom correspondence should be addressed; E-mail: anas@itqb.unl.pt

Received: 14 December 2007; in revised form: 25 February 2008 / Accepted: 25 February 2008 / Published: 3 March 2008

\begin{abstract}
The purpose of this work is to review the published strategies for the production of prodrugs of amines. The review is divided in two main groups of approaches: those that rely on enzymatic activation and those that take advantage of physiological chemical conditions for release of the drugs. A compilation of the most important approaches is presented in the form of a table, where the main advantages and disadvantages of each strategy are also referred.
\end{abstract}

Keywords: Prodrugs, amines, enzymatic activation, chemical activation

\section{Introduction}

The prodrug strategy may be defined as the temporary derivatisation of a functional group of a drug in order to improve its pharmaceutical utility. Sometimes the functional group is merely a handle for the introduction of a moiety that confers on the new entity some desirable characteristic; more frequently, the group is intimately connected with the pharmaceutical deficiency and its masking directly addresses the deficiency. Of the commonly occurring drug functional groups, perhaps greatest effort has been directed at temporarily masking the amino group. The most easily identified liability of candidate amino drugs is their tendency to ionise under physiological conditions, leading to poor 
membrane penetration by passive diffusion. The impact of this is amplified for the large number of amino drugs that are required to penetrate the blood brain barrier in order to reach their pharmacological targets. A second issue that can affect the development of amino drugs is instability. An example of this is the tendency of primary amines to undergo first-pass metabolism due to $\mathrm{N}$ acetylation and oxidation by monoaminooxidase (MAO) [1]. The same applies to peptides [2] containing basic amino acid side-chains. Low water solubility, poor stability and low permeability through biological membranes often hinder the clinical development of biologically active peptides [3]. The major problem in designing amine prodrugs is the general robustness of amine derivatives particularly those, such as amides, in which the capacity to ionize has been obviated. On the other hand, the very robustness of amino derivatives means that subtle drug targeting effects can be achieved if an appropriate local vector can be identified and accommodated in the design process. A number of prodrugs of cytotoxic agents fit this description. In structuring the review we have in the first instance sought to classify prodrugs according to whether in vivo activation is enzymatic or $\mathrm{pH} / \mathrm{redox}$ dependent. Within this major division the various types are identified by the nature of the derivative functional group. The approach is admittedly somewhat arbitrary as prodrug systems rarely undergo activation exclusively by one route. Also, a derivative type that undergoes unmasking enzymatically in one prodrug, may be removed primarily chemically in another because of overall structural differences. Finally, although peptides can be derivatised on other functionalities, we have included only those approaches that involve the amino group alone or conjointly with other functional groups. Table 1 presents a summary of the most important amine prodrug designs along with their dominant activation mechanism and the advantages/disadvantages of each approach. The table should be consulted where difficulties arise in identifying the chemical structure of a group from its name.

\section{Prodrugs that rely (mostly) on enzymatic activation}

\section{N-Alkylation}

Secondary and tertiary alkyl amines are reported to undergo dealkylation mediated by MAO-B to an amine and the corresponding aldehyde or ketone [4]. This has been investigated as a prodrug approach for the CNS active agent 2-phenylethylamine (PEA). In comparison with the free drug, $N, N$ dipropargyl-2-phenylethylamine and $N$-propargyl-2-phenylethylamine produced increased levels of PEA in the brain of rats [5,6]. $N$-(2-cyanoethyl)-2-phenylethylamine [7] and $N$-(3-chloropropyl)-2phenylethylamine (1) [8] also caused sustained elevations of PEA in rat brain.

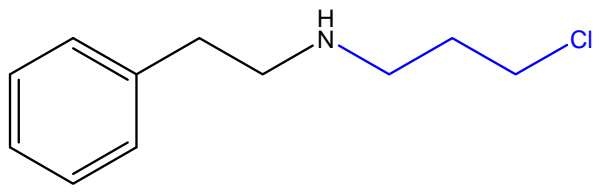


Table 1. Compilation of a series of published prodrug approaches to amine drugs.

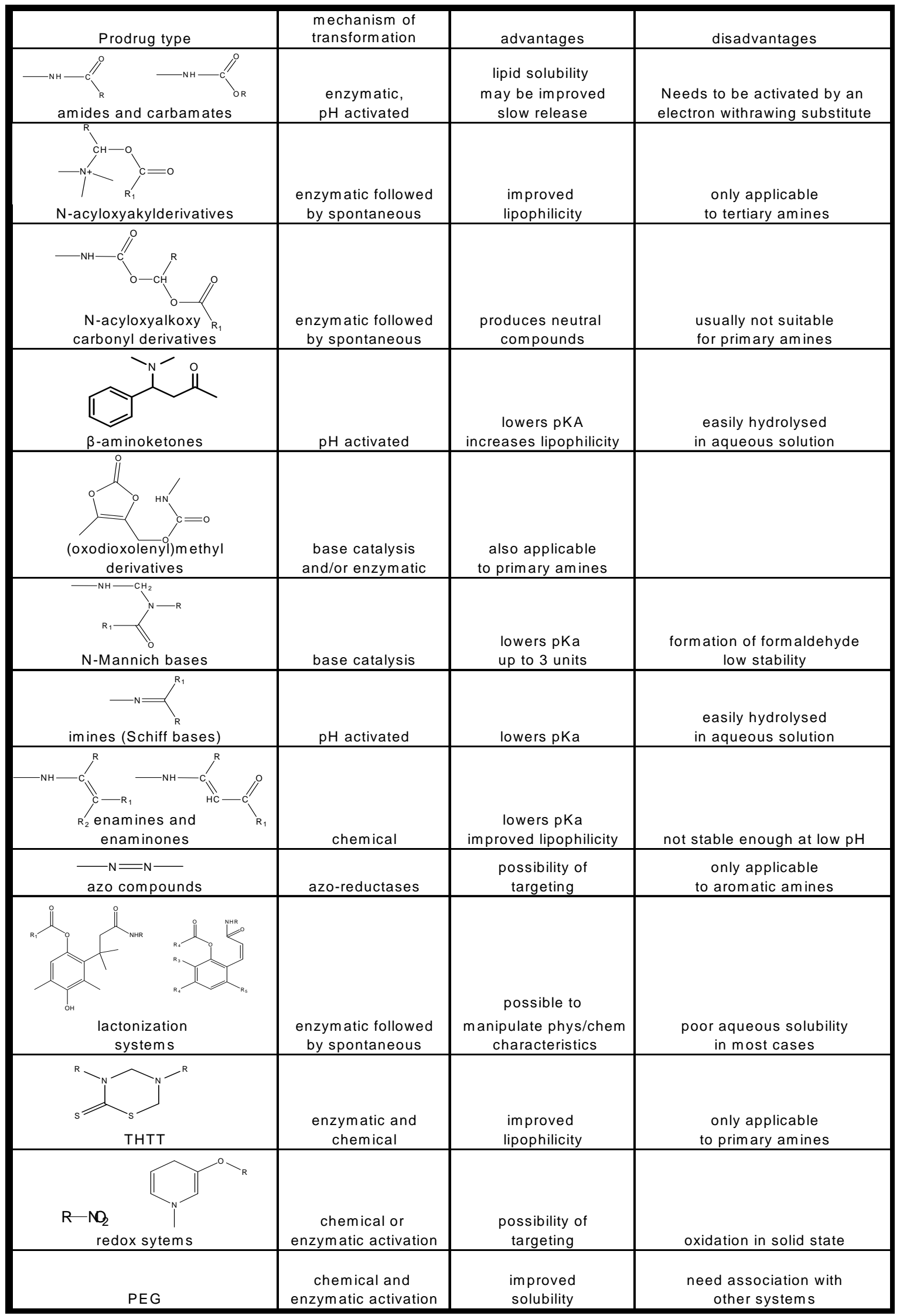




\section{$N$-Acylation: amides and simple carbamates}

Bioreversible masking of the hydroxyl group with an ester functionality is a practical prodrug approach as ester compounds are in general readily hydrolysed by the rich variety of hydrolase enzymes present in the human body. Acylation of amines is ostensibly less promising because of the chemical and enzymatic stability of amides and carbamates: in this context, mammalian amidases appear to be less promiscuous than esterases. Indeed amides also undergo hydrolysis by esterases in vitro [9], but the rates are usually too slow and insufficiently competitive to be used for amine release in vivo.

Nevertheless, several successful $N$-acyl prodrugs are in clinical use or in development. In some cases, activation relies on specific substrate-peptidase relationships while in others, slow prodrug hydrolysis by non-specific enzymes is not undesirable. A well-known example of the former is the exploitation of renal $\gamma$-glutamyl transpeptidase as a vector for amino drug release from $\gamma$-glutamic acid conjugates [10]. Dopamine has been a candidate for this and numerous other prodrug approaches because it is inactivated by sulfotransferase, MAO and COMT in the intestinal wall and liver [11] following oral administration [12]. The dopamine double prodrug, $\gamma$-glutamyl-L-dopa (gludopa), achieves kidney dopamine levels about five-fold higher than those obtained with an equimolar quantity of the single prodrug L-dopa [13]. Gludopa itself however, suffers from poor oral bioavailability [14].

Docarpamine, [ $\mathrm{N}$-( $\mathrm{N}$-acetyl-L-methionyl)-O,O-bis(ethoxycarbonyl)dopamine), 2], a pseudopeptide prodrug of dopamine, is administered orally in the treatment of renal and cardiovascular pathologies $[15,16]$.

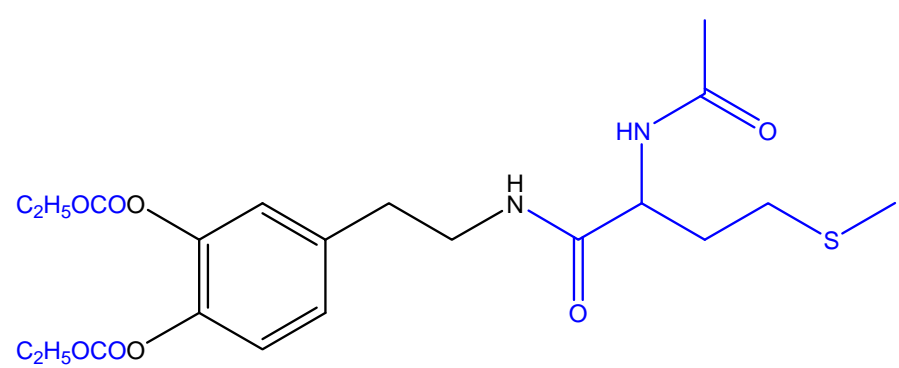

2

Docarpamine is well absorbed from the oral route, has weak intrinsic vasodilatory effects [17], has no effect in the CNS even at high doses [11], and is easily converted to dopamine in vivo [15]. Nonpeptide $\mathrm{N}$-acyl derivatives of dopamine have also been evaluated [18]. Several other amine conjugate with amino acids via amide bonds have been investigated with significant improvement in solubility, for example, dapsone $[19,20]$.

More recently, amino acids have been linked to anti-tumour amines to produce water-soluble amide prodrugs that release, in vivo, the parent amine [21]. Glycine and valine amides of monoaminooxidase A (MAO-A) inhibitors were also prepared as an attempt to deliver the active compounds to the brain before inhibiting MAO-A in the intestinal mucosa which leads to the potentiation of tyramine induced hypertension [22].

Derivatization with amino acids has also been used to target intestinal transporters such as PEPT1. One such case is the vasoconstrictor midodrine, which releases the active form 1-(2',5'-dimethoxyphenyl)-2-aminoethanol) following cleavage of the glycine residue [23]. 
One synthetic amide prodrug type system that has been extensively studied are the $N$-acyl derivatives of allopurinol, which are more lipophilic than the parent drug, while at the same time being in some cases more water soluble [24]. The acetyl, veleroyl and nicotinoyl amides of stobadine (3) are highly lipophilic and penetrate the BBB [25].

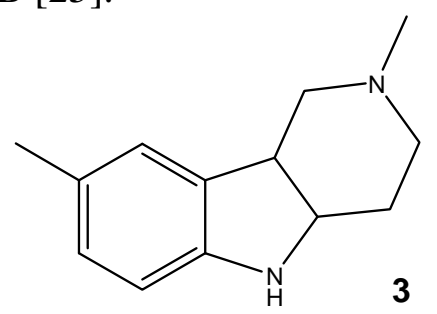

Simple $N$-acyl prodrugs in which slow cleavage is desirable are the [(2-sulfo)-9fluorenylmethoxycarbonyl]-3 derivatives of glucose lowering drugs like insulin [26] (4, R=H) and exendin-4 [27]. These prodrugs have the advantage of delivering the drugs slowly to the systemic circulation reducing the risk of hypoglycaemia.
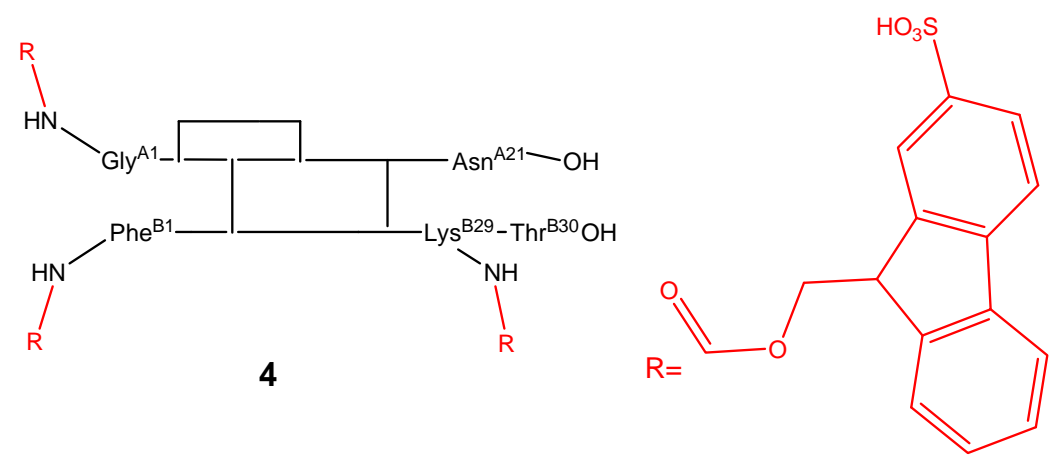

Another system that involves carbamate and urea prodrugs has been developed for antibodydirected enzyme prodrug therapy [ADEPT]. In this system, the carbamate and the urea groups are substrates for the enzyme tyrosinase present in melanomas, where it triggers the release of the drug [28]. New cephalosporins have also been subjected to acyl derivatisation in order to increase solubility [29]. The prototypical non-sedating antihistamine loratadine (5) is an ethyl carbamate, which undergoes a CP450-mediated conversion in vivo to the active desloratadine (6) [30]. It is interesting to note that loratadine was not designed in response to any apparent pharmaceutical liability in desloratadine, and it was certainly not clear at the outset that one acted as a precursor for the other [31].
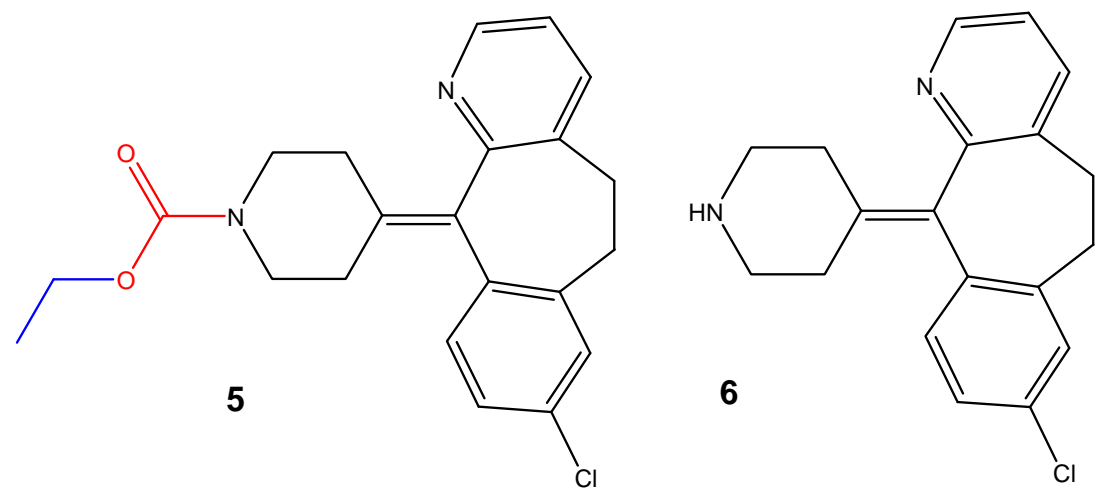
The anti-cancer drug capecitabine is a cascade-type prodrug that produces 5-fluorouracil (5-FU) in the liver and in response to enzymes overexpressed in cancer cells. The first step in the cascade is hydrolysis of a pentyl carbamate mediated by liver carboxylesterase (CES-1). Significant species differences were observed when a panel of homologous carbamates was subjected to hydrolysis by human, monkey and mouse carboxylesterases and the discovery scientists point out that the correct analogue would not have been selected for development without the availability of human intestinal and liver carboxylesterases [32]. Capecitabine has lower gastrointestinal toxicity than 5FU, better tumour targeting and is widely used now clinically [33]. Pentyl PABC-Doxaz (PPD) is a doxaz carbamate prodrug that contains a pentylcarbamate of an anilide, though in this case hydrolysis is mainly mediated by human intestinal carboxylesterase (CES-2) [34]. Neither of these pentyl carbamates is an amine prodrug in the truest sense, since in neither case is the pharmacologically active moiety an amine. However they illustrate that carbamates of anilides may be processed by intestinal or liver carboxylases, predominantly CES-2 or CES-1 respectively.

\section{$N$-Acyloxyalkylation, $N$-hydroxyalkylation and $N$-(phosphoryloxy)alkylation}

$N$-Acyloxyalkyl derivatives of primary and secondary amines are not usually suitable as prodrugs due to their high lability in aqueous solution. However, with tertiary or $N$-heterocyclic amines it is possible to produce stable quaternary ammonium salts that are nonetheless susceptible to enzymatic hydrolysis by esterases and subsequent spontaneous decomposition. An example of this type is the tetradecyloxymethyl quaternary salt of pilocarpine (7) [35].

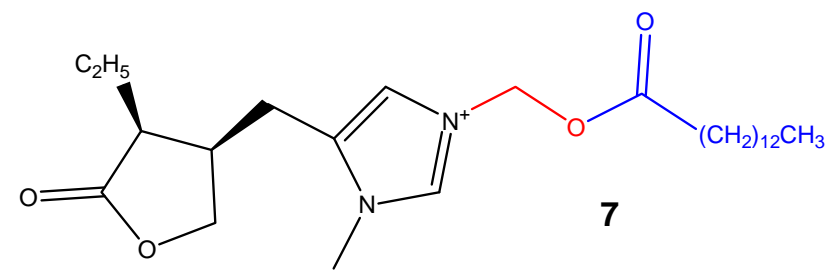

$\mathrm{N}$-acyloxyalkyl derivatives $\mathbf{8}$ of the topical antiproliferative drug theophylline have been evaluated. No increase in skin permeability was apparent with alkyl chains of up to five carbons; however, the intermediate 7-hydroxymethyltheophylline, possesses twice the permeability of the drug itself [36].

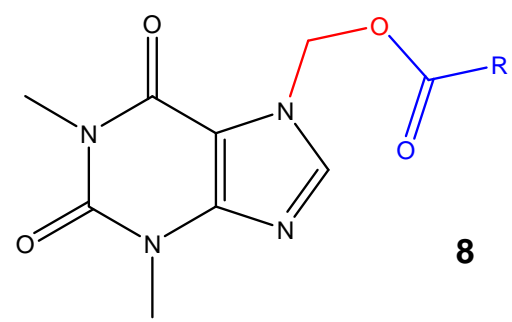

Some quaternary derivatives of tertiary amines have been mentioned as potential prodrugs since these compounds degrade at physiological $\mathrm{pH}$ releasing the parent amine [10] in a similar fashion to the acyloxyalkyl derivatives. Another approach involves a salt form of an $N$-phosphoryloxymethyl prodrug, from which the parent drug is released by a first step enzyme-catalysed rate-determining dephosphorylation, followed by spontaneous chemical breakdown of the $N$-hydroxymethyl intermediate [37]. This approach which has been applied to loxapine, improves the aqueous solubility 
and stability of the drug [38] and in vivo tests suggest that there is quantitative reversion of the prodrug to the parent drug [39]. The phosphoryloxymethyl spacer approach has also been successfully employed in fosphenytoin (Scheme 1), a prodrug of the anti-epileptic phenytoin [40].

Scheme 1. Tripartite prodrug system for tertiary amines (illustrated for fosphenytoin).
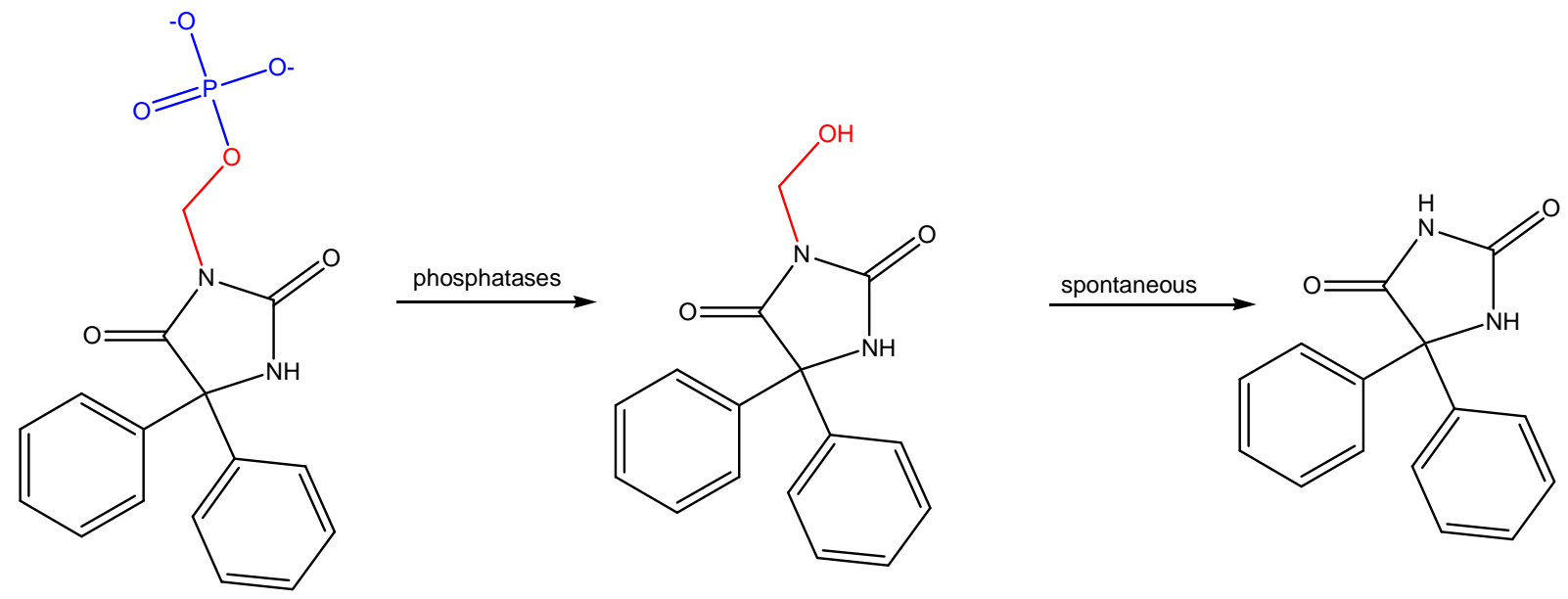

(Acyloxy)alkyl and (phosphoryloxy)alkyl carbamates

$\mathrm{N}$-Acyloxyalkoxycarbonyl derivatives or (acyloxy)alkyl carbamates $\left(\mathrm{R}_{4}=\right.$ alkyl or aryl), have received attention as possible prodrug types for amines [41-44]. The compounds possess an esterase sensitive terminal group, whose hydrolysis triggers a spontaneous decomposition of the intermediate (hydroxyalkoxy)carbonyl derivative liberating the parent amine (Scheme 2). This approach neatly addresses the relative enzymatic stability of simple $N$-acyl groups.

Scheme 2. Hydrolysis of (acyloxy)alkyl carbamate and amine prodrugs.<smiles>[R]NN[R2]</smiles>

The system has limited applicability to primary amines whose $\mathrm{N}$-acyloxyalkoxycarbonyl adducts can undergo intramolecular acyl transfer, leading to the formation of stable $N$-acyl compounds (Scheme 3) [45]. 
Scheme 3. Intramolecular acyl transfer in $N$-acyloxyalkoxycarbonyl derivatives of primary amines.

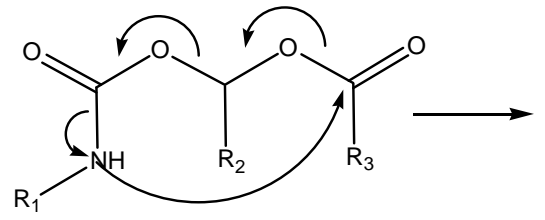<smiles>[R]NC([R3])=O</smiles><smiles>[R]C=O</smiles>

(Acyloxy)alkyl carbamates derivatives of hydrophilic beta-blockers exhibited several fold increase in rat skin and rabbit cornea permeation in comparison with the original drugs [46]. Other examples of (acyloxy)alkyl carbamates are the taste-masking prodrugs $\mathbf{9}$ of the bitter anti-bacterial norfloxacin (10) [47] and XP13512, a prodrug of gabapentin recognized by MCT1 and the sodium-dependent multivitamin transporter (SMVT) [48]. XP13512 was efficiently absorbed and rapidly converted to gabapentin after oral dosing. In monkeys, the oral bioavailability of gabapentin from XP13512 was about $84 \%$ compared to $25 \%$ after similar oral administration of gabapentin [49].<smiles>Cn1cc(C(=O)O)c(=O)c2cc(F)c(N3CCNCC3)cc21</smiles>

9

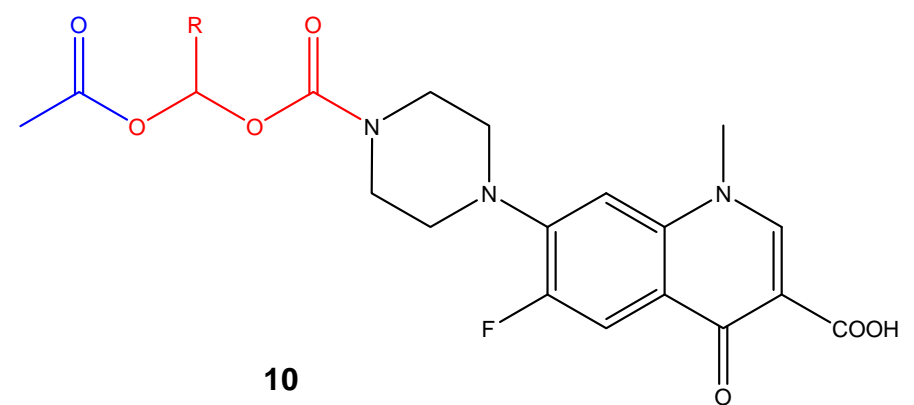

The use of (acyloxy)methyl esters as bridging groups (Scheme 2, $\mathrm{R}_{2}=\mathrm{H}$ ) is generally a topic of controversy due to the generation of formaldehyde during breakdown. For this reason, (acyloxy)ethyl esters (Scheme 2, $\mathrm{R}_{2}=\mathrm{CH}_{3}$ ) are usually preferred. On the other hand, (acyloxy)ethyl derivatives introduce a chiral centre into the system; if the drug already has a chiral centre, diastereomers are formed, which can display very different hydrolytic rates [50].

(Alkoxycarbonyloxy)methyl carbamates have also been prepared (Scheme 2, $\mathrm{R}_{4}=$ alkoxy or aryloxy) [43], as well as (phosphoryloxy)methyl carbamates $\mathbf{1 1}$ which would, in vivo, be cleaved by alkaline phosphatases. In vitro tests with the phosphate esters showed that following the initial enzymatic triggering, a spontaneous cascade leads to the release of the amine [51].<smiles>[R]N([R])C(=O)OCOP(=O)([O-])[O-]</smiles>

\section{Azo compounds}

Numerous azo compounds have been investigated as site-specific prodrugs that exploit the facile reduction of the azo linkage by azo-reductase enzymes. A remarkable story of an early amine azo prodrug is that of Prontosil (12), which was used for the treatment of streptococcal infections. Prontosil is a prodrug of sulphanilamide (13) and it was developed by Gerhard Domagk in 1932, 
probably for commercial reasons rather than pharmacokinetic ones, as the active compound was not patentable. A group at the Pasteur Institute later speculated that the azo link might not be necessary for therapeutic efficacy, and that the active principal might be formed by reduction of the azo bond. They later proved that the antibacterial activity resided in the sufanilamide portion of the molecule [52].
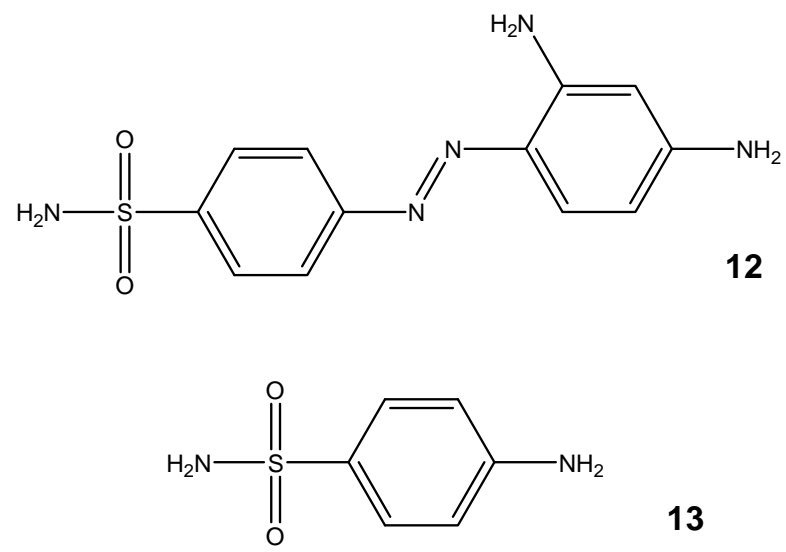

A well-known azo-drug class that exploits azoreductases for site-specific drug release are the 5aminosalicylic acid prodrugs (e.g. olsalazine, 14). These pass unaffected through the intestine where they are poorly absorbed $[10,45]$, but are reduced by azoreductases associated with the high levels of colonic bacteria.

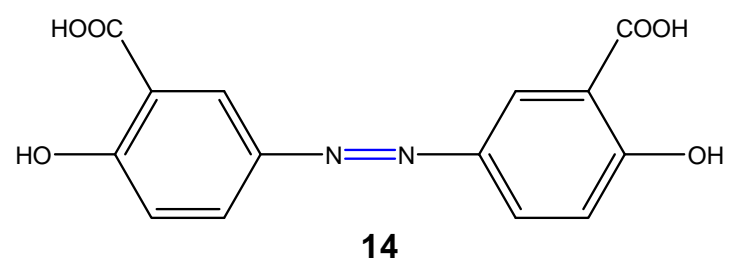

Other clinically used prodrugs in this class include balsalazide and ipsalazide, in which the 5aminosalicylic acid moiety is conjugated to 4-aminobenzoyl- $\beta$-alanine and 4-aminobenzoylglycine, respectively [53]. It should be noted that the azo-approach is generally restricted to primary aromatic amines, azo derivatives of aliphatic amines being unstable. More recently, conventional $N$-acyl type conjugates of 5-aminosalicylic acid with various amino acid derivatives were evaluated for colon specific delivery. 5-Aminosalicylic acid-L-aspartic acid was effectively delivered to the large intestine, releasing about half of the administered dose of 5-aminosalicylic acid [54].

\section{Redox systems}

The design of prodrug systems poised to undergo redox reaction receives growing attention. The principal merit of this type of drug-release triggering mechanism is its potential to achieve site-specific delivery. For example, several reductive systems which are selectively activated in hypoxic conditions have been developed and applied in cancer therapy. The systems involve amines latent as nitro groups which, after conversion, form adducts with DNA. The reduction pathway involves several radical intermediates as well as nitroso, hydroxylamine and amine intermediates (Scheme 4). 
Scheme 4. Generalised reduction pathway for nitro-heterocycles [55].

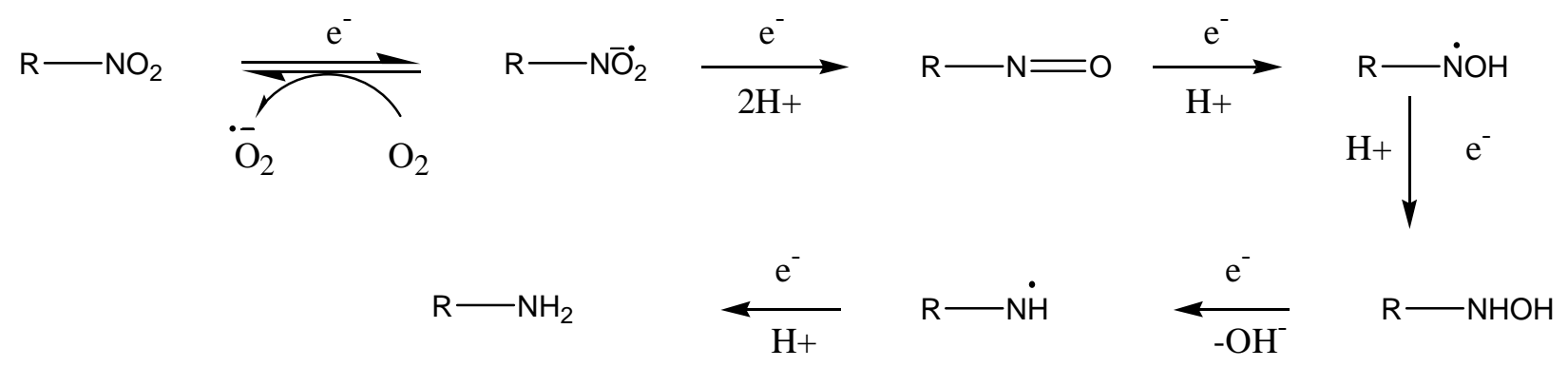

This type of drug delivery system has been evaluated for the 2-nitroimidazoles, mitomycin C, tirapazamine [55] and indolequinones [56], amongst others. The reduction can be facilitated by the action of endogenous or specially delivered enzymes [ADEPT or GDEPT]. A similar approach has been applied to aromatic mustards $\mathbf{1 5}$ to produce prodrugs to target hypoxic tumours. Although the direct use of nitroaromatic mustards $\mathbf{1 6}$ could be envisaged as a hypoxic activated system, its application is limited because both the nitro and the alkylating groups are attached to the same aromatic rings and have opposing electronic requirements. This means that the prodrug has a very low reduction potential with consequent low hypoxic selectivity. Substitution on the aromatic ring with electron-withdrawing groups greatly reduced the cytotoxicity of the drug [57]. Nevertheless a watersoluble phosphate ester of a 3,5-dinitrobenzamide-2-nitrogen mustard is currently under clinical trials. The prodrug is converted in vivo to the corresponding alocohol and afterwards activated by reduction to the corresponding 5-hydroxylamine and 5-amine [58].
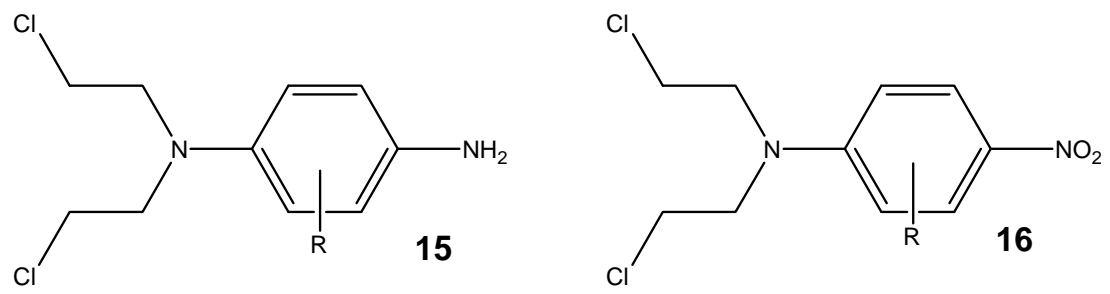

However, the design of a reductively activated system where the reduction potential can be manipulated independently $\left(\mathrm{R}_{1}\right)$ allows the production of prodrugs of the more cytotoxic nonsubstituted mustards. Moreover, the selection of the linker group X (Scheme 5) allows some control over the rates of cyclization [57].

A series of $\mathrm{N}$-dinitrophenylamino acid amides that also release primary amines via nitroreduction and intramolecular cyclization has been studied. This system does not seem to be efficiently activated by nitroreductases but the reduction can be radiation-induced, which is a possible approach in cancer therapy [59]. 
Scheme 5. Mechanism of activation of 2-aminoaryl derivatives.

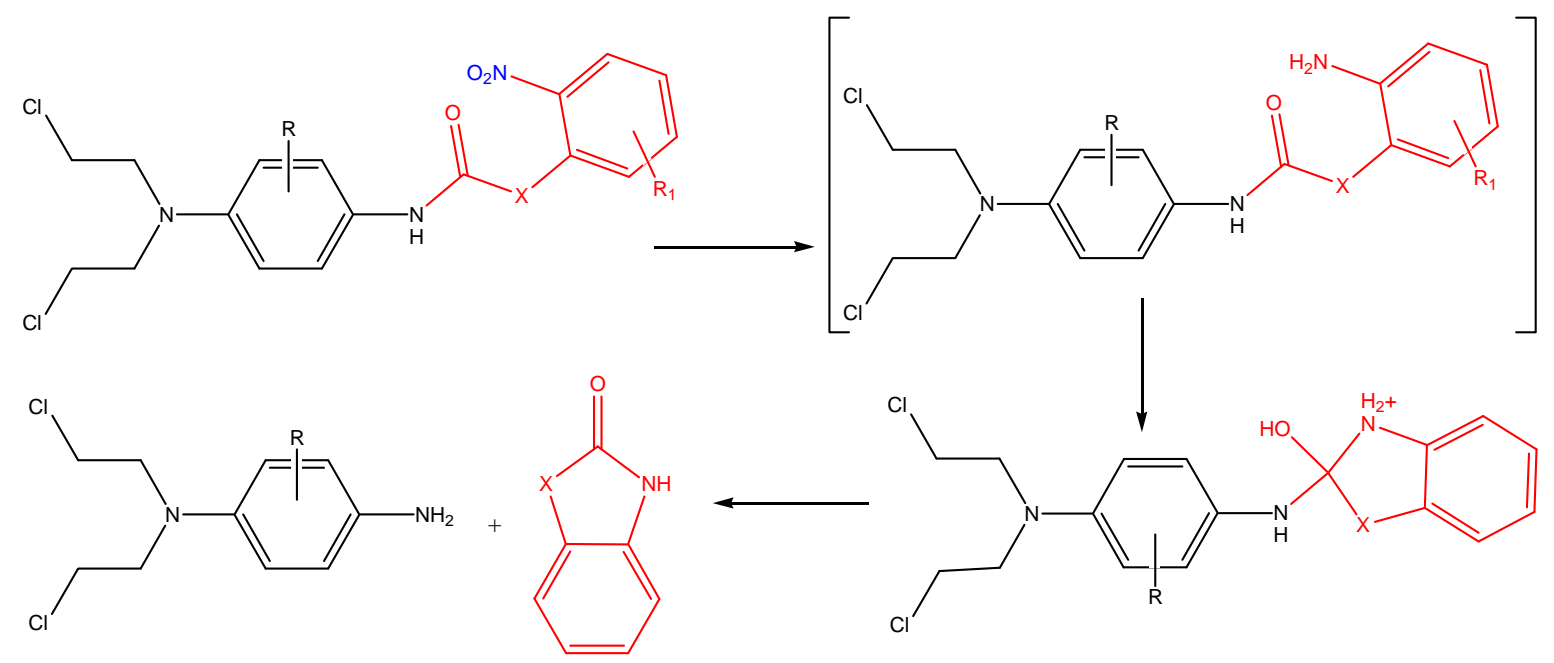

Another system that can be activated by reduction is the 4-azidobenzyloxycarbonyl (Scheme 6). In this system the drug is linked through a carbamate to an aromatic azide that is converted by reduction to an amine: a cascade reaction eliminates the carbamic acid, which is readily converted to the amine drug [60].

Scheme 6. Activation of the 4-azidobenzyloxycarbonyl prodrug system.<smiles>CCOC(=O)Nc1ccc(N(C)C)cc1</smiles><smiles>CC(C)(C)C(=O)Nc1ccc([N+](=O)[O-])cc1</smiles>

$\mathrm{N}$-oxides have been suggested as bioreductive prodrugs for tertiary amines. $\mathrm{N}$-oxidation masks the cationic charge of the amine reducing their DNA binding affinity and toxicity. The prodrugs are activated by metabolic reduction under hypoxic conditions [61].

The dihydropyridinepyridinium salt system [62,63] (Scheme 7) is an example of a site-specific prodrug, developed for brain penetration of amines (but that is also applicable to alcohols and carboxylic acids), which employs an oxidative pathway for prodrug localisation. Application of this system to amines was illustrated for desipramine, amongst others. In this case, although there was no 
evidence of a more efficient delivery, there was a prolonged presence of the drug in the rat brain at a constant level [64].

Scheme 7. Redox carrier system to the brain.
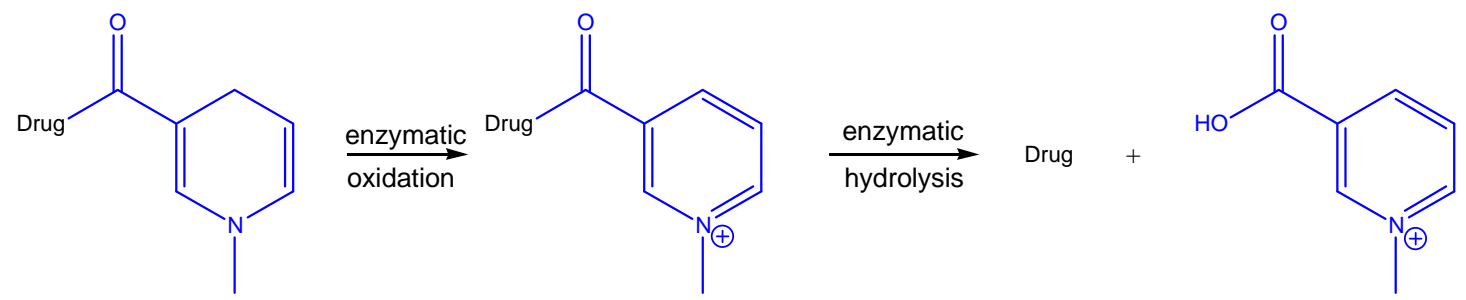

The system has also been applied to dopamine [65,66]. A dimeric form of this progroup has also been used [17]. The system has also been modified to include an activated carbamate ester $\mathbf{1 7 .}$

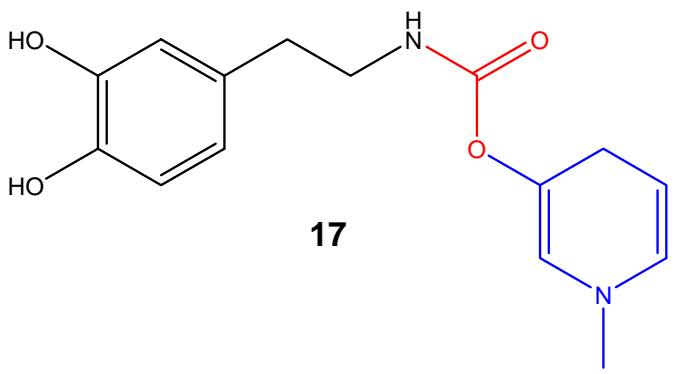

The relatively lipophilic prodrug penetrates the BBB and the salt obtained after oxidation is trapped in the brain, where it slowly releases the drug. Any oxidation in periphery results in rapid elimination of the intermediate due to its high polarity. This way, the drug can be preferentially accumulated in the brain. The approach has wide applicability to other functional groups such as alcohols and carboxylic acids $[67,68]$. One significant limitation to the design is the facile oxidation of the dihydropyridine function, which makes the development of a stable formulation difficult [13]. The application of this method to several different drugs has been reviewed [69]. An analogous thiazolium system [70] and carrier groups that involve alkoxycarbonyl methyl derivatives of 7,4-dihydropyridine3,5-dicarboxilate [71] have been proposed to overcome the stability problems of the dihydropyridine type prodrugs.

\section{PEG and other macromolecular systems}

Double prodrug systems that consist of poly(ethylene glycol) (PEG) linked through a spacer to the amine drug (18) have been explored for drug solubilization and for extending the plasma half-life of the drug. In one approach, ester, carbonate, carbamate or amide bonds are introduced as spacers and triggers for enzymatic activation and release of the PEG group. After that, the drug, latentiated in the form of a carbamate or an ester, is released by a spontaneous 1,4- or 1,6-benzyl elimination [72,73]. 


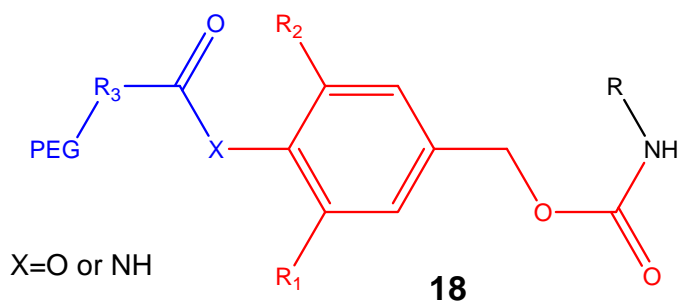

PEG can also be used in conjunction with the "trimethyl lock" system to produce prodrugs for amines with improved solubility and potentially capable of targeting specific tumors. In this system, which has been applied to Daunorubicin, PEG is connected through a spacer to the phenol group of the open lactone. Manipulation of the spacer or the substituents in the aromatic ring allows for tuning of release rates [73-76]. Analogous conjugates have been prepared for Doxorubicin with different results from the ones obtained for Daunorubicin [77], revealing that individual compounds should be evaluated with different linkers in order to determine the most effective combination.

Low molecular weight proteins (LMWP) have also been used to prepare systems for kidney targeting that can be cleaved by aminopeptidases or lysosomal lysates. The LMWP can also be linked to the drug through an acid sensitive spacer. Using $\beta$-naphthylamine ( $\beta$-naph) as a model compound, it was found that the Leu- $\beta$-naph and the Gly-Phen- $\beta$-naph conjugates were stable in buffer solution, but released the amine completely in cortex homogenates and lysosomal lysates solutions. However the results were not as promising with adriamycin, triametrene and sulfamethoxasole as model drugs [78].

Dextran conjugates have also been prepared using aminocarboxilic acids as spacers [79]. The concept has been applied for slow release of Mitomycin C; different release rates were observed for different linkers.

\section{Prodrugs that rely mostly on chemical activation}

\section{$\beta$-aminoketones}

A recently reported design involves the preparation of $\beta$-aminoketones, which are usually stable in acidic conditions but cleave into the parent amine and an $\alpha, \beta$-unsaturated ketone at neutral to basic $\mathrm{pH}$ [80,81]. Elimination from $\beta$-aminoketones by retro-Michael reaction is well known, but hadn't been used previously in prodrug systems for amines. Placement of the amine in a benzylic position seems to have a positive effect on the rate of elimination in comparison with aliphatic systems. This is probably due to the extended conjugation of the double bond upon elimination of the amine.

Half-lives at $\mathrm{pH}=7.4$ range from less than one minute to several hours depending on the amine and on the progroup. The indanone prodrug of atenolol $\mathbf{1 9}$ has a half-life of 1.3 minutes in $\mathrm{pH}=7.4$ buffer and 2.3 minutes in plasma. 


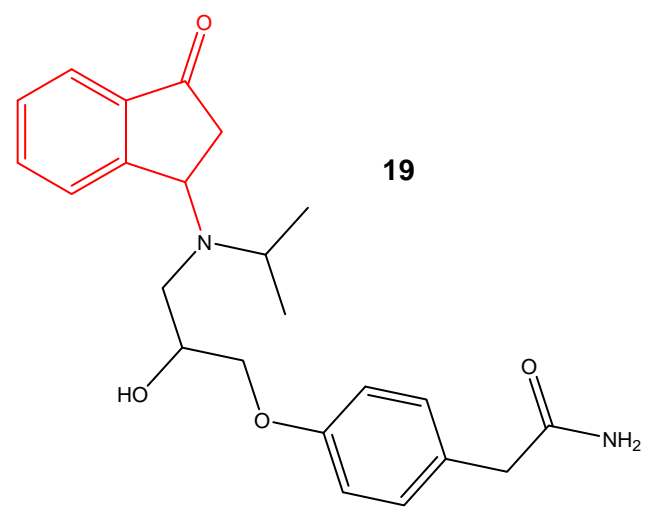

\section{Schiff bases}

Imines (Schiff bases), are usually too easily hydrolysed to be useful as amine prodrugs. Nevertheless, in some particular cases they may be surprisingly stable and useful as they impart increased lipophilicity to the parent amine and depress the pKa values. The anticonvulsant progabide under the trade name Gabrene ${ }^{\odot}$ (20) was prepared as a prodrug form of $\gamma$-aminobutyric acid (GABA) since it crosses the BBB, while the free drug doesn't. The prodrug is converted to $\gamma$-aminobutiramide and GABA (Scheme 8), which are then trapped if produced in the brain. However, it might not be considered a true prodrug as it possesses intrinsic pharmacological activity [10].

Scheme 8. Metabolism of progabide.

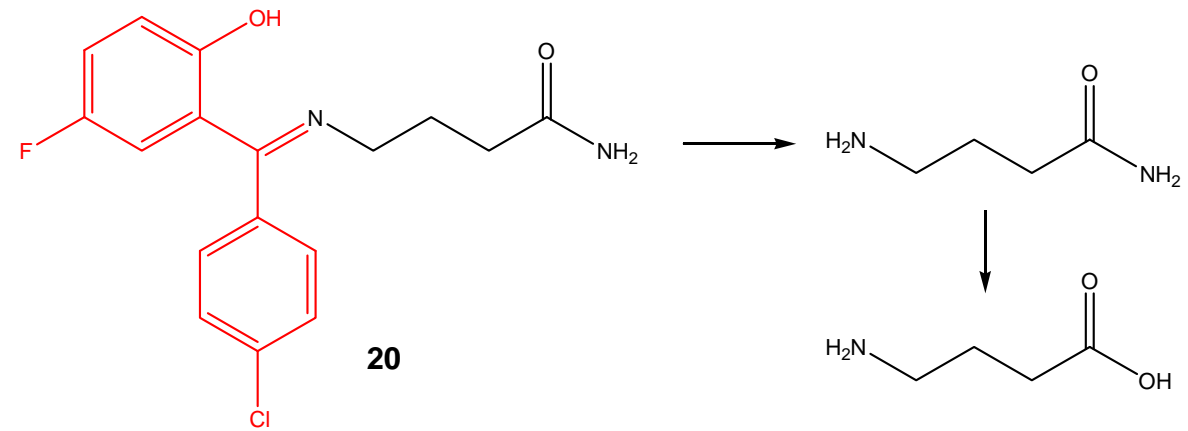

Chemically activated azomethine prodrugs 21 [82,83] of the reference histamine H3 receptor agonist $R$ - $\alpha$-methylhistamine have been evaluated, as well as enzymatically [84] activated prodrugs (amide, esters and carbamates).

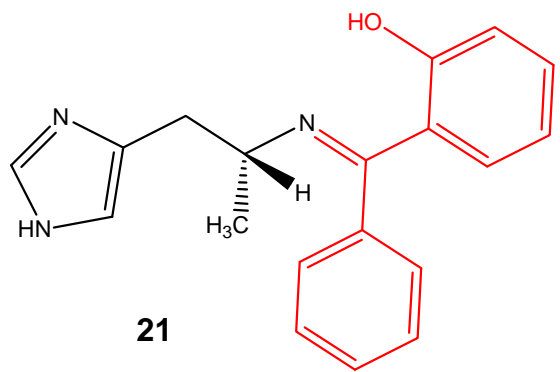

The new compounds, being more lipophilic, have improved oral absorption and better BBB penetration than the original drug. 


\section{$S$ and N-Mannich bases}

$\mathrm{N}$-Mannich bases are synthesised through the Mannich reaction, which involves a $\mathrm{NH}$-acidic compound, an aldehyde (usually formaldehyde) and an amine in ethanol (Scheme 9).

Scheme 9. Synthesis of $N$-Mannich bases.<smiles>[R]NN[R2]CCC([R])=O</smiles>

This system can be used to produce prodrugs that are more soluble than the parent [85], not only for amines but also for amides, as in the case of rolitetracycline [45]. $N$-Mannich bases are useful when an increase in the lipophilicity of amines is desirable. $\mathrm{N}$-Mannich base formation also suppresses the pKa (a difference of up to 4 units) with respect to the amine, which means that an important proportion remains unionized at the $\mathrm{pH}$ of the intestine [1]. However, the range of biologically acceptable amide type transport groups affording an appropriate cleavage rate is limited [86].

Cleavage of the prodrug in this case is strictly $\mathrm{pH}$ dependent: it has been found that $\mathrm{N}$-Mannich bases of salicylamide and different aliphatic amines and amino acids show a bell shaped $\mathrm{pH} / \mathrm{rate}$ profile with a high breakdown rate at $\mathrm{pH}$ 7.4. In the case of salicylamide, the hydroxyl group is thought to be responsible for the high reactivity, possibly by intramolecular catalysis, when the compound is in the neutral or zwitterionic forms. At high $\mathrm{pH}$, when the compound is in the anionic form, the reactivity decreases markedly [87]. However, derivatisation of this group by acyloxymethylation, provides new possibilities of controlling in vivo cleavage as well as improved in vitro stability (Scheme 10) [88].

Scheme 10. Esterase sensitive $N$-Mannich bases of salicylamide as prodrugs for amines.<smiles>[R]N[R]Nc1ccccc1C(=O)NCN([R2])CCOc1ccccc1C(=O)NCN([R])[R]</smiles> 
It was established that the acidity of the parent amide and steric effects within the amine component correlate with reactivity [85,89]. For amines with similar steric properties, a decreasing basicity is associated with decreasing reactivity [85]. For example, the rate of breakdown of $\mathrm{N}$ Mannich bases of aromatic amines with succinamide increases markedly with increasing amine basicity [1]. For amines with similar pKas, some correlation was found between reaction rates and the difference in pKa between the amine and the corresponding Mannich base (for the same amide) [90].

A drawback of the $N$-Mannich bases is their limited in vitro stability, raising some stability/formulation problems [45]. The unavoidable release of formaldehyde during decomposition is another factor that has to be taken into consideration due to its toxicity [85].

An example of an S-Mannich base is dipyrone (metamizole) the methanesulfonic acid of the analgesic 4-(methylamino)antipyrine, which is highly water soluble and therefore more suitable for parenteral administration. When administered orally, dipyrone appears to undergo fast hydrolysis in the stomach followed by intestinal absorption of the active form [91].

\section{(Oxodioxolenyl)methyl carbamates and other selfimmolative systems}

(Oxodioxolenyl)methyl carbamates were prepared as an attempt to avoid the drawbacks of (acyloxy)ethyl and (acyloxy)methyl esters. The prodrugs break by base catalysis according to Scheme 11 , but the rate of hydrolysis in plasma solutions is higher than in $\mathrm{pH} 7.4$ buffer solutions $[43,50]$.

Scheme 11. (Oxodioxolenyl)methyl carbamate prodrugs of amines: mechanism of basecatalysed cleavage.

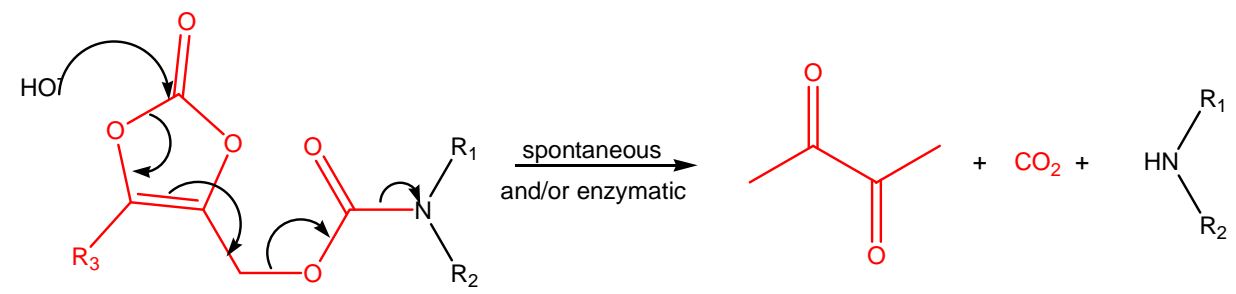

In these systems, the cleavage of the dioxolenone ring by the amino group attack on the reactive vinylene carbonate function is precluded, which makes this approach potentially applicable to primary amines. Aryl $\mathrm{R}_{3}$ substituents generally have a destabilising influence, reducing the half-life of the prodrugs [50]. The system has been applied to pseudomycins and some of the prodrugs exhibited comparable in vivo efficacy to that achieved by the parent compounds, with reduced side effects [92].

In a similar approach a selfimmolative linker was used to attach tryptophan to a bisphosphonate component through a carbonate-labile linker, 4-hydroxy-3,5-dimethoxybenzyl alcohol, which was further attached through a stable carbamate linkage to the amine group of tryptophan [93]. The carbonate linkage hydrolysed with a half-life of $90 \mathrm{~h}$, but it can be modulated through the nature of the substituent on the aromatic ring of the self-immolative linker.

Another example using oxodioxolenyl group is that of Prulifloxacin (Scheme 12) which is a fluoroquinolone antibacterial agent with a broad spectrum of activity against Gram-positive and -negative bacteria [94] currently under clinical phase 3 trials. The prodrug uses the (5-methyl-2oxo-1,3-dioxolyl)methyl promoiety linked to the secondary amine group of the active form by $\mathrm{N}$ alkylation. Amine release is triggered by esterase attack on a distal oxodioxolenyl group, but formally 
speaking, the connection to the amine group being masked is an alkyl group. Prulifloxacin is available for oral use, and after absorption is metabolized to the active form ulifloxacin by esterases, mainly paraoxonase [95].

Scheme 12. Enzymatic hydrolysis of Prulifloxacin [95].

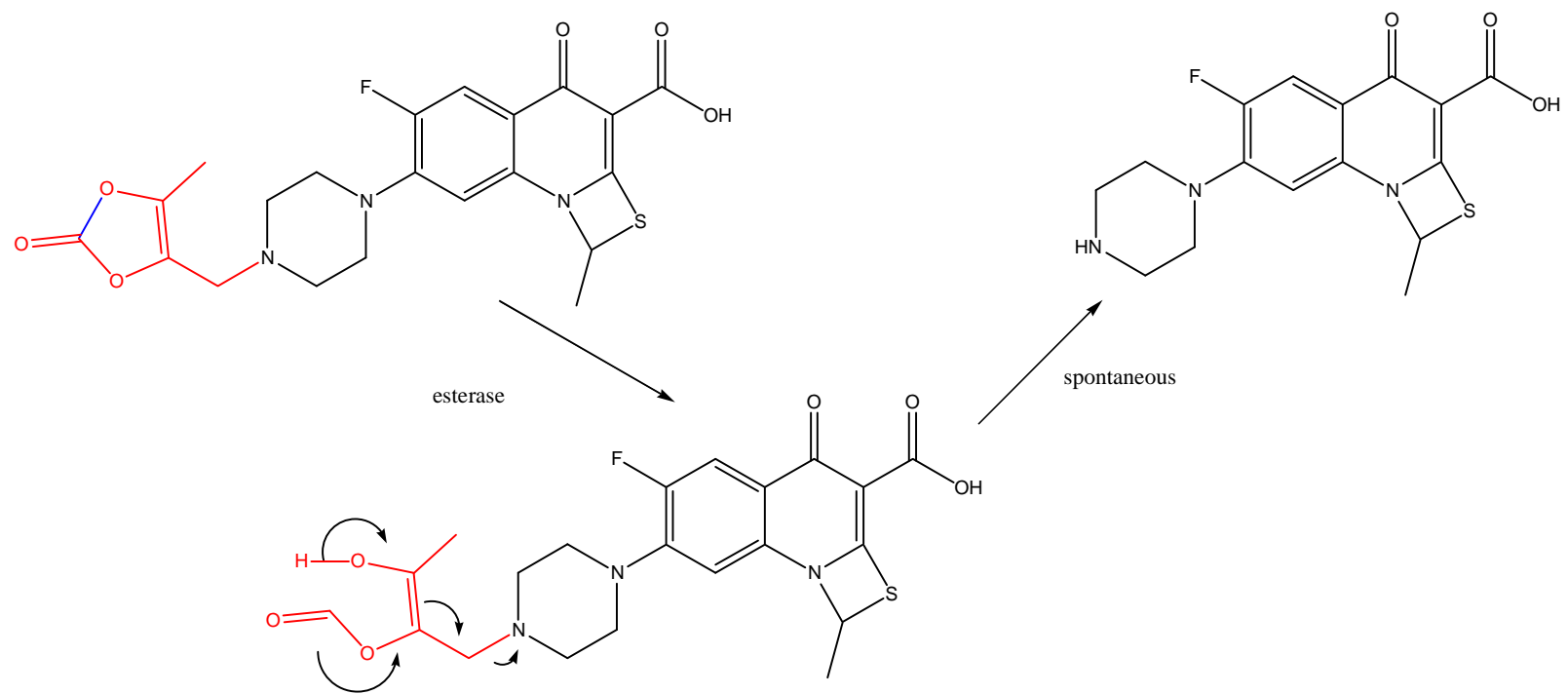

Enamines and enaminones

Enamines [96], ( $\alpha, \beta$-unsaturated amines), just like imines, are generally unstable particularly at low $\mathrm{pH}$, which make them unsuitable for the preparation of prodrugs for oral delivery. Nevertheless, an enamine prodrug of ampicillin was found to promote the rectal absorption of the drug [97]. Enaminones, which are enamines of $\beta$-dicarbonyl compounds are more stable, probably due to ketoenol and imine-enamine tautomeric equilibria (Scheme 13) [91], and were thought to have potential use as prodrugs [10].

Scheme 13. Stabilisation of enaminones.<smiles>[R]C(=O)CC([R6])=N[B]</smiles><smiles>C=C=C</smiles><smiles>[R9]N=C([R9])/C=C(/[R])O</smiles>

The hydrolysis of enaminones derived from some amino acids and antibiotics is rapid, releasing the amine and a diketone (Scheme 14). 
Scheme 14. Hydrolysis of enaminones.<smiles></smiles>

The prodrugs are more lipophilic than the corresponding drugs, which usually results in improved absorption [10]. The system seems to be relatively insensitive to the type of amine used, but very sensitive to minor changes in the structure of the 1,3-dicarbonyl compound used to produce the prodrug. Closed structures like the compounds derived from cyclohexane-1,3-dione show considerably lower rates of hydrolysis. This is probably due to their rigid geometry and the inherent stability of this system. The maximum rate of hydrolysis occurs in the $\mathrm{pH}$ range 2-5 [98].

Based on chemical stability considerations, enaminones do not seem promising as prodrugs. However it has been speculated that enaminones obtained from ketoesters and lactones may be better candidates as they may be subjected to enzyme-catalysed degradation [99].

\section{"Trimethyl lock" and coumarin systems}

Phenolic amides derived from lactones can be used as amine prodrug systems as they release the amine and a lactone at physiological $\mathrm{pH}$ [100] (Scheme 15). In this system, referred to generally as a "trimethyl lock", the side chain is folded back to bring the amide carbonyl group into proximity with the nucleophilic phenolic oxygen. This conformation may account for the facile cyclisation that occurs independently of the drug attached to the side chain. However the half-lives of these systems are usually less than $1 \mathrm{~min}$, which is too short for useful application [101].

Scheme 15. "Trimethyl lock" prodrug system for amino drugs.
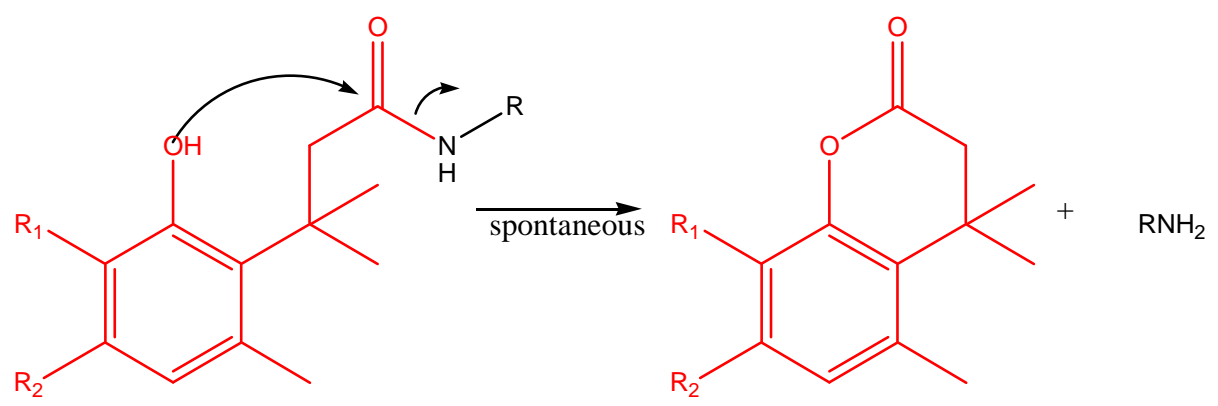

The design has been has been modified to produce compounds that are esterase [102] or redox [103] sensitive (Figure 1). These derivatisations involve the protection of the nucleophilic hydroxyl in a bioreversible manner. The rate-limiting step then becomes the enzymatic exposure of the phenolic group. A further variation to this system involved the introduction of phosphate esters as the phenolic masking group [104]. 
Figure 1. Tripartite "trimethyl lock" systems.

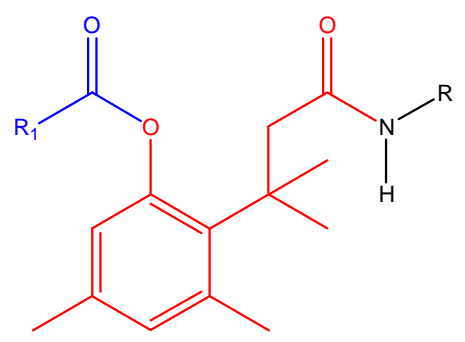

Esterase sensitive

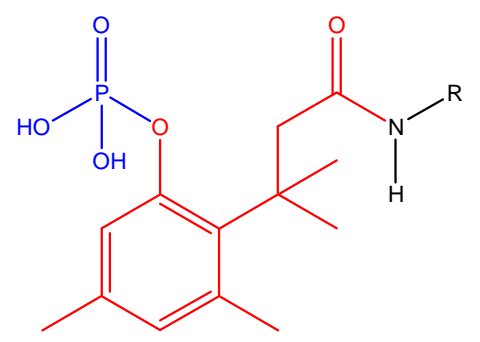

Alkaline phosphatase sensitive

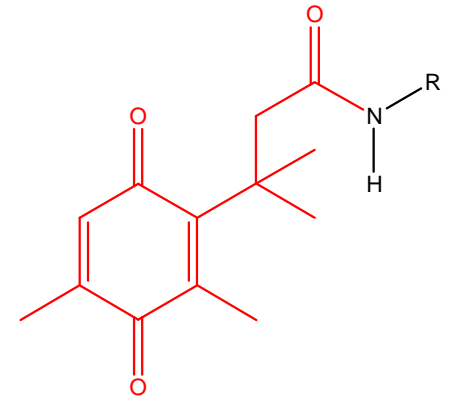

redox sensitive

A conceptually similar system exploits the facile cyclization of coumarinic acid and its derivatives [105] (Scheme 16). The presence of the phenolic hydroxyl group and the cis-geometry of the double bond allows lactonization at rates comparable to those of the "trimethyl lock" system. The phenol group is protected by an ester or a phosphate group that serves as an esterase or phosphatase sensitive biological triggering mechanism.

Scheme 16. Coumarin-based esterase sensitive system for amino drugs.
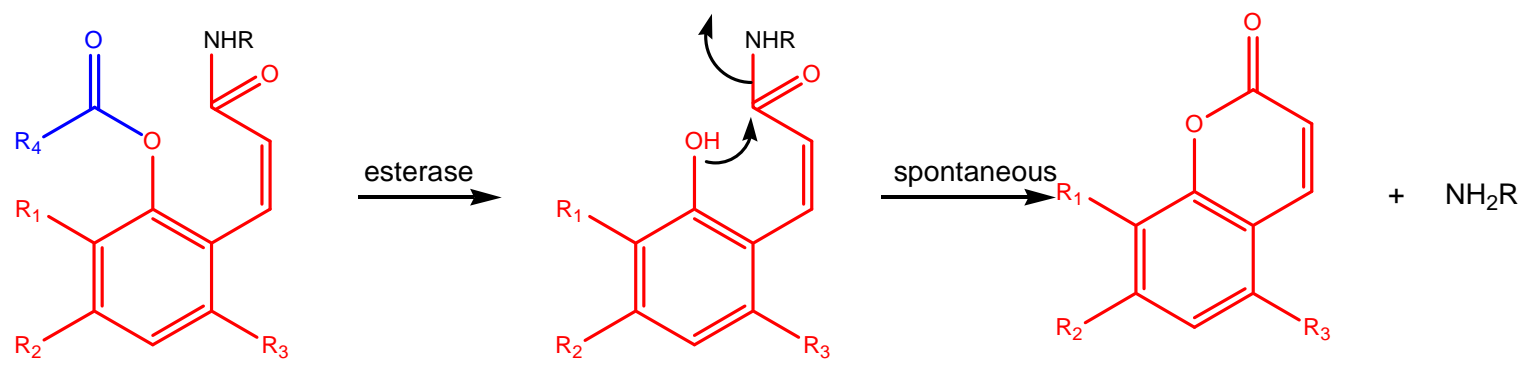

The lactonization rate is higher for primary amines than for secondary amines; it also depends on steric features of the amine to be released [106]. For secondary amines with higher pKas, the system is sometimes undesirably slow. A further refinenment to the design is the use of ring mesomeric effects to tune drug release rates: increases of up to 16-fold can be achieved by placing electron releasing groups on the aromatic ring [107,108].

More recently, an attempt was made to prepare a tripartite prodrug (double prodrug) that uses the coumarin system as a spacer between the drug (linked to the side chain) and a carrier group, a peptide or an amino acid, connected to the hydroxyl group of the coumarin. The advantage of this system would be the possibility of targeting drug specific proteases for the cleavage that would release the carrier, which would be followed by spontaneous lactonization, releasing the drug. Poor aqueous solubility has, however, limited the exploitation of this system [109].

\section{THTT}

A tetrahydrothiadiazine-2-thione (THTT, Figure 2) was proposed as a prodrug system for primary amines [110], amino acids [111] and peptide drugs [112]. In this system the nitrogen atom from the drug is included in a six membered ring, which is more lipophilic than the original drug. The prodrugs 
are enzyme and chemically sensitive at physiological $\mathrm{pH}$, but are stable under acidic conditions. Despite the apparent promise of this system, it does not seem to have been subjected to further development.

Figure 2. THTT prodrug system for amines and amino acids.<smiles>[R]N1CSC(=S)N([R])C1</smiles>

\section{Cyclic derivatives of polyfunctional drugs containing the amino group}

Making prodrugs of compounds with multiple functional groups may be a challenge, particularly in the case of peptides, where the amine group poses a problem of its own due to the lack of suitable biologically reversible masking groups. The "trimethyl lock" and coumarin systems mentioned before as prodrug systems for amines, have also been tested as prodrugs for peptides (linked to the progroup through an amide and an ester link) with promising results (Figure 3) [113-116].

Figure 3. Coumarin system applied to peptides.

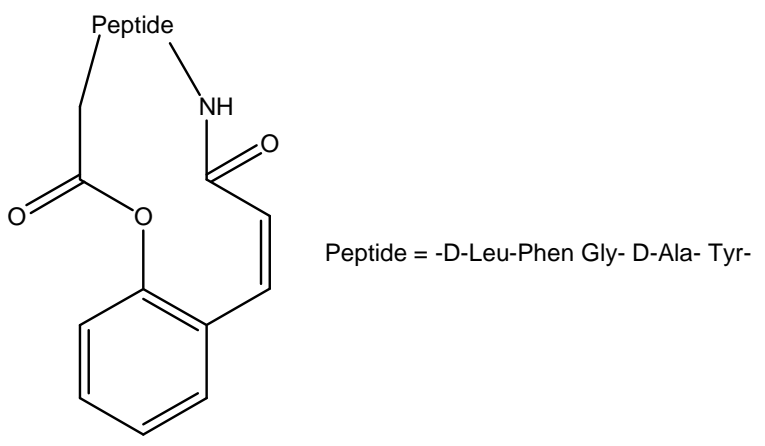

The concept has been applied to peptides such as DADLE, an opioid peptide. The $C$ and $N$ terminal ends of the linear peptide are masked by forming an ester and an amide bond with the phenol hydroxyl and side chain carboxyl groups, respectively, of the linker [107]

Oxazolidines 22, which are cyclic condensation products of $\beta$-aminoalcohols and aldehydes or ketones, are a possible means of formation of peptide prodrugs [86]. These compounds are less basic and more lipophilic than the corresponding $\beta$-aminoalcohols and hydrolyse completely in aqueous solution [117]. Thiazolidines can be used for $\beta$-aminothiols.

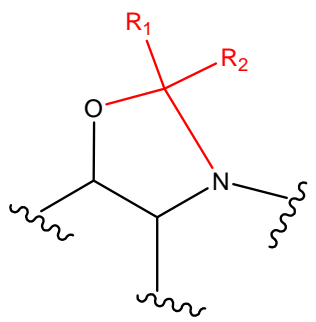<smiles>[Z6]C1NC([R])([R])N(S)C1=O</smiles> 
4-Imidazolidinones 23 [118-120] have been proposed for the $\alpha$-aminoamide moiety, in particular as prodrugs of Leu-enkephalin and prilocaine. The derivatives of Leu-enkephalin afford protection against aminopeptidase- $\mathrm{N}$ and angiotensin converting enzyme (ACE) and are cleaved slowly in buffered solutions at $\mathrm{pH}=7.4$, with half-lives of some hundred minutes [120]. The hydrolysis of some prilocaine derivatives, at basic pHs, proceeds to an equilibrium due to reversible kinetics [119]. Lactams and pyrrolines have been shown to revert to the corresponding amino acids by enzymatic action. Moreover, they pass the BBB while the opened structures don't. One example is the cyclic derivative (24) of GABA depicted in Scheme 17.

Scheme 17. Conversion of 2-pyrrolidinone to GABA.

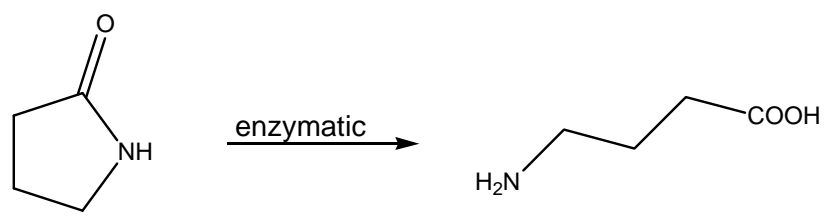

24

\section{Conclusions}

Three major themes emerge in amine prodrug chemistry: (i) suppression of ionization in order to promote passive diffusion; (ii) increasing the metabolic stability especially of primary amines and peptides; (iii) tissue targeting, particularly tumor tissue targeting. Other objectives include increasing the water solubility of the amine. Overall then, amino drugs may benefit significantly from prodrug design, but designing appropriate prodrugs for amines has been challenging. This challenge has provoked a markedly disparate variety of responses from pharmaceutical researchers. We considered it timely to gather these into one review article as a sort of catalogue that developers might find useful to consult during the development of new amino drugs or improvement of existing ones. Predicting the suitability of any single approach to a new situation, however, is still problematic. It seems prudent to investigate a number of approaches in parallel with appraisal in a panel of the most relevant human biological matrices, for example, intestinal and liver microsome preparations as well as plasma.

\section{References}

1. Bundgaard, H.; Johansen, M. Prodrugs as drug delivery systems. XIX. Bioreversible derivatisation of aromatic amines by formation of $N$-Mannich bases with succinimide. Int. $J$. Pharm. 1981, 8, 183-192.

2. Bundgaard, H. Prodrugs as a means to improve the delivery of peptide drugs. 1. Adv. Drug Deliv. Rev. 1992, 8, 1-38.

3. Wang, W.; Jiang, J.; Ballard, C.; Wang, B. Prodrug approaches to the improved delivery of peptide drugs. Curr. Pharm. Des. 1999, 5, 265-287.

4. Gasparro, D.M.; Almeida, D.R.P.; Pisterzi, L.F.; Juhasz, J.R.; Viskolcz, B.; Penke B.; Csizmadia, I.G. Reaction profiling of the MAO-B catalyzed oxidative deamination of amines in Alzheimer's disease J. Mol. Struct.: THEOCHEM 2003, 666-667, 527-536. 
5. Testa, B.; Mayer, J.M. Hydrolysis in Drug and Prodrug metabolism, Chemistry, biochemistry and enzymology. Wiley-VCH: Weinheim, 2003; Chapter 4, p. 83.

6. Rao, T.S.; Baker, G.B.; Coutts, R.T. N,N-dipropargyl-2-phenylethylamine, a potential prodrug of 2-phenylethylamine: neurochemical and neuropharmacological studies in rat. Brain Res. Bull. 1987, 19, 47-55.

7. Rao, T.S.; Baker, G.B.; Coutts, R.T. Pharmacokinetic and neurochemical studies on $N$-propargyl2-phenylethylamine, a prodrug of 2-phenylethylamine. N.-S. Arch. Pharmacol. 1987, 336, 25-32

8. Baker, G.B.; Coutts, R.T.; Rao, T.S. Neuropharmacological and neurochemical properties of $N$ (2-cyanoethyl)-2-phenylethylamine, a prodrug of 2-phenylethylamine. Br. J. Pharmacol. 1987, 92, 243-255.

9. Rao, T.S.; Baker, G.B.; Coutts, R.T. N-(3-chloropropyl)phenylethylamine as a possible prodrug of beta-phenylethylamine: studies in the rat brain. Prog. Neuropsychopharmacol. Biol. Psychiatry 1987, 11, 301-308.

10. Bundgaard, H. In Design of prodrugs; Bundgaard, H., Ed.; Elsevier: Amsterdam, 1985; Chapter 1.

11. Nishiyama, S.; Yoshikawa, M.; Yamaguchi, I. An orally effective peripheral dopamine prodrug Docarpamine TA-870. Cardiovasc. Drug Rev. 1992, 10, 101-116.

12. Casagrande, C.; Merlo, L.; Ferrini, R.; Miragoli, G.; Semeraro, C. Cardiovascular and renal action of dopaminergic prodrugs. J. Cardiovasc. Pharmacol. 1989, 14, S40-S59.

13. Kearney, A.S. Prodrugs and targeted drug delivery. Adv. Drug Deliv. Rev. 1996, 19, 225-239.

14. Lee, M. Five years experience with $\gamma$-L-glutamyl-L-dopa- a relatively renally specific dopaminergic prodrug in man. J. Auton. Pharmacol. 1990, 10, S103-S108.

15. Matsubayashi, K.; Ueda, Y.; Ogino, H.; Sugita, T.; Sakakibara, Y.; Matsuyama, K.; Nomoto, T. Oral administration of the dopamine prodrug docarpamine shortens need for drip infusion of dopamine in patients with low cardiac output syndrome after cardiac surgery. Thorac. Cardiovasc. Surg. 1999, 47, 352-356.

16. Tano, K.; Yoshizumi, M.; Kitagawa, T.; Hori, T.; Kitaichi, T.; Itoh, K.; Katoh, I. Effect of docarpamine, a novel orally active dopamine prodrug, on the formation of free and sulfoconjugated dopamine in patients who underwent cardiac surgery. Life Sci. 1997, 61, 14691478.

17. Nishiyama, S.; Yamaguchi, I.; Akimoto, Y.; Yoshikawa, M.; Nakajima, H. A novel orally active dopamine prodrug TA-870 II. Evidence that TA-870 is a dopamine prodrug. J. Cardiovasc. Pharmacol. 1989, 14, 175-183.

18. Carelli, V.; Liberatore, F.; Scipione, L.; Impicciatore, M.; Barocelli, E.; Cardellini, M.; Giorgioni, G. New systems for the specific and sustained release of dopamine to the brain. J. Control. Release 1996, 42, 209-216.

19. Pochopin, N.L.; Charman, W.N.; Stella, V.J. Pharmacokinetics of Dapsone and Amino Acid Prodrugs of Dapsone. Drug Metab. Dispos. 1994, 22, 770-775.

20. Pochopin, N.L.; Charman, W.N.; Stella, V.J. Amino Acid Derivatives of Dapsone as WaterSoluble Prodrugs. Int. J. Pharm. 1995, 121, 157-167.

21. Bradshaw, T.D.; Bibby, M.C.; Double, J.A; Fichtner, I.; Cooper, P.A.; Alley, M.C.; Donohue, S.; Stinson, S.F.; Tomaszewjski, J.E.; Sausville, E.A.; Stevens, M.F. Preclinical evaluation of amino 
acid prodrugs of novel antitumor 2-(4-amino-3-methylphenyl)benzothiazoles. Mol. Cancer. Ther. 2002, 1, 239-246.

22. Florvall, L.; Fagervall, I.; Larson, L.; Ross, S.B. Prodrugs of neuron-selective monoamine oxidase inhibitors: amino acid derivatives of 1-(4-aminophenyl)-2-aminopropanes. Eur. J. Med. Chem. 1999, 34, 137-151.

23. Tsuda M.; Terada T.; Irie M.; Katsura T.; Niida A.; Tomita K.; Fujii N.; Inui K.J. Transport characteristics of a novel peptide transporter 1 substrate, antihypotensive drug midodrine, and its amino acid derivatives. Pharmaco.l Exp. Ther. 2006, 318, 455-460.

24. Bundgaard, H.; Falch, E. Allopurinol prodrugs. I. Synthesis, stability and physicochemical properties of various N1-acyl allopurinol derivatives. Int. J. Pharm. 1985, 23, 223-237.

25. Stankoviov, M. Kinetics of hydrolysis of acetyl, valeroyl and nicotinoyl acyl derivatives of stobadine. Life Sci. 1999, 65, 2007-2010.

26. Gershonov, E.; Goldwaser, I.; Fridkin, M.; Shechter, Y. A novel approach for a water-soluble long acting insulin prodrug: design, preparation, and analysis of [(2-sulfo)-9fluorenylmethoxycarbonyl]3-insulin. J. Med. Chem. 2000, 43, 2530-2537.

27. Shechter, Y.; Tsubery, H.; Fridkin, M. [(2-sulfo)-9-fluorenylmethoxycarbonyl]3-exendin-4 a long acting glucose-lowering prodrug. Biochem. Biophys. Res. Commun. 2003, 305, 386-391.

28. Jordan, A.; Khan, T.; Malkin, H.; Osborn, H. Synthesis and analysis of urea and carbamate prodrugs as candidates for melanocyte-directed enzyme prodrug therapy (MDEPT). Bioorg. Med. Chem. 2002, 10, 2625-2633.

29. Hecker, S.J.; Calkins, T.; Price, M.E.; Huie, K.; Chen, S.; Glinka, T.W; Dudley, M.N. Prodrugs of Cephalosporin RWJ-333441 (MC-04,546) with improved aqueous solubility. Antimicrob. Agents Chemother. 2003, 47, 2043-2046.

30. Yumibe, N.; Huie, K.; Chen, K.J.; Snow, M.; Clement, R.P.; Cayen, M.N. Identification of human liver cytochrome P450 enzymes that metabolize the nonsedating antihistamine loratadine. Formation of descarboethoxyloratadine by CYP3A4 and CYP2D6. Biochem Pharmacol. 1996, 51, 165-172.

31. Monroe, E. Desloratadine for the treatment of chronic urticaria, Skin Therapy Lett. 2002, 7, 1-2,5.

32. Shimma, N.; Umeda, I.; Arasaki, M.; Murasaki, C.; Masubuchi, K.; Kohchi, Y.; Miwa, M.; Ura, M.; Sawada, N.; Tahara, H.; Kuruma, I.; Horii, I.; Ishitsuka, H. The design and synthesis of a new tumor-selective fluoropyrimidine carbamate, capecitabine. Bioorg Med Chem. 2000, 8, 16971706.

33. Ajani, J. Review of capecitabine as oral treatment of gastric, gastroesophageal, and esophageal cancers. Cancer 2006, 107, 221-231.

34. Barthel, B.L.; Torres, R.C.; Hyatt, J.L.; Edwards, C.C.; Hatfield, M.J.; Potter, P.M.; Koch, T.H. Identification of human intestinal carboxylesterase as the primary enzyme for activation of a doxazolidine carbamate prodrug. J. Med. Chem. 2008, 51, 298-304.

35. Järvinen, T.; Järvinen, K. Prodrugs for improved ocular drug delivery. Adv. Drug Deliv. Rev. 1996, 19, 203-224.

36. Kerr, D.; Roberts, W.; Tebbett, I.; Sloan, K. /-Alkylcarbonyloxymethyl prodrugs of theophylline: topical delivery of theophylline. Int. J. Pharm. 1998, 167, 37-48. 
37. Krise, J.P.; Zygmunt, J.; Georg, G.I; Stella, V.J. Novel prodrug approach for tertiary amines: synthesis and preliminary evaluation of $N$-phosphonooxymethyl prodrugs. J. Med. Chem. 1999, 42, 3094-3100.

38. Krise, J.P.; Narisawa, S.; Stella, V.J. A novel prodrug approach for tertiary amines. 2. Physicochemical and in vitro enzymatic evaluation of $N$-phosphonooxymethyl prodrugs. $J$. Pharm. Sci. 1999, 88, 922-927.

39. Krise, J.P.; Charman, W.N.; Charman, S.A.; Stella, V.J. A novel prodrug approach for tertiary amines. 3. In vivo evaluation of two $N$-phosphonooxymethyl prodrugs in rats and dogs. J. Pharm. Sci. 1999, 88, 928-932.

40. Stella, V.J. A Case for Prodrugs: Fosphenytoin. Adv. Drug Del. Rev. 1996; 19, 311-330.

41. Gogate, U.S.; Repta, A.J.; Alexander, J. N-(acyloxyalkoxycarbonyl) derivatives as potential prodrugs for amines. I. Kinetics and mechanism of degradation in aqueous solutions. Int. J. Pharm. 1987, 40, 235-248.

42. Gogate, U.S.; Repta, A.J. N-(acyloxyalkoxycarbonyl) derivatives as potential prodrugs for amines. II. Esterase-catalysed release of parent amines from model prodrugs. Int. J. Pharm. 1987, 40, 249255.

43. Li, Z.; Bitha, P.; Lang, S.; Lin, Y. Synthesis of (alkoxycarbonyloxy)methyl, (acyloxy)methyl and (oxodioxolenyl)methyl carbamates as bioreversible prodrug moieties for amines. Bioorg. Med. Chem. Lett. 1997, 22, 2909-2912.

44. Bodor, N. in Design of prodrugs; Bundgaard, H., Ed.; Elsevier: Amsterdam, 1985; Chapter 11.

45. Krogsgaard-Larsen, P.; Liljefors, T.; Madsen U. A textbook of drug design and discovery; 3rd ed.; Taylor and Francis: New York, 2002; Chapter 14, pp. 410-458.

46. Alexander, J.; Cargyl, R.; Michelson, S.; Schwam, H. (Acyloxy)alkyl carbamates as novel bioreversible prodrugs for amines: increased permeation through biological membranes. J. Med. Chem. 1988, 31, 318-322.

47. Alexander, J.; Fromtling, R.; Bland, J.; Pelak, B.; Gilfillan, E. (Acyloxy)alkyl carbamate prodrugs of norfloxacin. J. Med. Chem. 1991, 34, 78-81.

48. Cundy, K.C.; Branch, R.; Chernov-Rogan, T.; Dias, T.; Estrada, T.; Hold, K.; Koller, K.; Liu, X.; Mann, A.; Panuwat, M.; Raillard, S.P.; Upadhyay, S.; Wu, Q.Q.; Xiang, J.N.; Yan, H.; Zerangue, N.; Zhou, C.X.; Barrett, R.W.; Gallop, M.A. XP13512 [(+/-)-1-([( $\alpha$-isobutanoyloxyethoxy)carbonyl]aminomethyl)-1-cyclohexane acetic acid], a Novel Gabapentin Prodrug: I. Design, Synthesis, Enzymatic Conversion to Gabapentin, and Transport by Intestinal Solute Transporters. J. Pharmacol. Exp. Ther. 2004, 311, 315-323.

49. Cundy, K.C.; Annamalai, T.; Bu, L.; De Vera, J.; Estrela, J.; Luo, W.; Shirsat, P.; Torneros, A.; Yao, F.; Zou, J.; Barrett, R.W.; Gallop, M.A. XP13512 [(+/-)-1-([( $\alpha$-isobutanoyloxyethoxy)carbonyl] aminomethyl)-1-cyclohexane acetic acid], a Novel Gabapentin Prodrug: II. Improved Oral Bioavailability, Dose Proportionality, and Colonic Absorption Compared with Gabapentin in Rats and Monkeys. J. Pharmacol. Exp. Ther. 2004, 311, 324-333.

50. Alexander, J.; Bindra, D.; Glass, J.; Holahan, M.; Reyner, M.; Rork, G.; Sitko, G.; Stranieri, M.; Stupienski, R.; Veerpanane, H.; Cook, J. Investigation of (oxodioxolenyl)methyl carbamates as nonchiral bioreversible prodrug moieties for chiral amines. J. Med. Chem. 1996, 39, 480-486. 
51. Safadi, M.; Oliyai, R.; Stella, V.J. Phosphoryloxymethyl carbamates and carbonates - novel water soluble prodrugs for amines and hindered alcohols. Pharm. Res. 1993, 10, 1350-1355.

52. Kirshner, J. The origin of 20th century discoveries transforming clinical gastroenterology. Am. J. Gastroenterol. 1998, 93, 862-871.

53. Sandborn, W. Rational selection of oral 5-aminosalicylate formulations and prodrugs for the treatment of ulcerative colitis. Am. J. Gastroenterol. 2002, 97, 2939-2941.

54. Jung, Y.; Lee, J.; Kim, Y. Colon-specific prodrug of 5-aminosalicylic acid: synthesis and in vitro/in vivo properties of acidic amino acid derivatives of 5-aminosalicylic acid. J. Pharm. Sci. 2001, 90, 1767-1775.

55. Rauth, A.; Melo, T.; Misra, V. Bioreductive therapies: an overview of drugs and their mechanism of action. Int. J. Radiat. Oncol. Biol. Phys. 1998, 42, 755-762.

56. Everett, S.; Swann, E.; Naylor, M.; Stratford, M.; Patel, K.; Tian, N.; Newman, R.; Vojnovic, B.; Moody, C.; Wardman, P. Modifying rates of reductive elimination of leaving groups from indolequinone prodrugs: a key factor in controlling hypoxia-selective drug release. Biochem. Pharmacol. 2002, 63, 1629-1639.

57. Atwell, G.; Sykes, B.; O'Connor, C.; Denny, W. Relationships between structure and kinetics of cyclization-activated aromatic mustards. J. Med. Chem. 1994, 37, 371-380.

58. Guise, C.P.; Wang, A.T.; Theil, A.; Bridewell, D.J.; Wilson, W.R.; Patterson, A.V. Identification of human reductases that activate the dinitrobenzamide mustard prodrug PR-104A: a role for NADPH:cytochrome P450 oxidoreductase under hypoxia. Biochem. Pharmacol. 2007, 74, 810820.

59. Sykes, B.; Atwell, G.; Hogg, A.; Wilson, W.; O'Connor C.; Denny W. N-substituted 2-(2,6dinitrophenylamino)propanamides: novel prodrugs that release a primary amine via nitroreduction and intramolecular cyclization. J. Med. Chem. 1999, 42, 346-355.

60. Griffin, R.; Evers, E.; Davison, R.; Gibson, A.; Layton, D.; Irwin, W. The 4azidoberazyloxycarbonyl function: application as a novel protecting group and potential prodrug modification for amines. J. Chem. Soc. Perkin Trans. 1 1996, 11, 1205-1211.

61. Wilson, W.; Denny, W.; Pullen, S.; Thompson, K.; Li, A.; Patterson, L.; Lee, H. Tertiary amines $\mathrm{N}$-oxides as bioreductive drugs: DACA $\mathrm{N}$-oxide, nitracarine $\mathrm{N}$-oxide and AQ4N. $\mathrm{Br}$. J. Cancer 1996, 27, S43-S47.

62. Bodor, N.; Sheck, E.; Higuchi, T. Delivery of a quaternary pyridinium salt across the blood-brain barrier by its dihydropyridine derivative. Science 1975, 190, 155-156.

63. Bodor, N.; Farag, H.; Brewster, M.; Site-specific, sustained release of drugs to the brain. Science 1981, 217, 1370-1372.

64. Pop, E.; Wu, M.; Shek, E.; Bodor, N. Chemical delivery systems for drugs containing an amino group: synthesis and properties of some pyridine derivatives of desipramine. Drug. Des. Deliv. 1989, 5, 93-115.

65. Bodor, N.; Simpkins J. Redox delivery system for brain-specific, sustained release of dopamine. Science 1983, 221, 65-67.

66. Simpkins, J.; Bodor, N.; Enz A. Direct evidence for brain-specific release of dopamine from a redox delivery system. J. Pharm. Sci. 1985, 10, 1033-1036. 
67. Brewster, M.; Bodor, N. Improved brain delivery of antiviral agents through the use of redox targeting. Adv. Drug Deliv. Rev. 1994, 14, 177-197.

68. Pop, E.; Sot, F.; Anderson, W.; Panetta, J.; Estes, K.; Bodor, N.; Brewster, M. Redox targeting of LY231617, an antioxidant with potential use in the treatment of brain damage. Int. J. Pharm. 1996, 140, 33-44.

69. Prokai, L.; Prokai-Tatri, L.; Bodor, N. Targeting drug to the brain by redox chemical delivery systems. Med. Res. Rev. 2000, 20, 367-416.

70. Ishikura, T.; Senou, T.; Ishiara, H.; Kato, T.; Ito, T. Drug delivery to the brain. DOPA prodrugs based on a ring-closure reaction to quaternary thiazolium compounds. Int. J. Pharm. 1995, 116, 51-63.

71. Sheha, M.; Al-Tayeb, A.; El-Sherief, H.; Farag, H. New carrier for specific delivery of drugs to the brain. Bioorg. Med. Chem. 2003, 11, 1865-1872.

72. Greenwald, R.; Pendri, A.; Conover, C.; Zhao, H.; Choe, Y.; Martinez, A.; Shum, K.; Guan, S. Drug delivery systems employing 1,4- or 1,6-elimination: poly(ethylene glycol) prodrugs of amine-containing compounds. J. Med. Chem. 1999, 42, 3657-3667.

73. Greenwald, R. PEG drugs: an overview. J. Control. Release 2001, 74, 159-171.

74. Greenwald, R.; Choe, Y.; Conover, C.; Shum, K.; Wu, D.; Royzen, M. Drug delivery systems based on trimethyl lock lactonization: poly(ethylene glycol) prodrugs of amine-containing compounds. J. Med. Chem. 2000, 43, 475-487.

75. Greenwald, R.; Zhao, H.; Xia, J. Tripartate poly(ethylene glycol) prodrugs of the open lactone form of camptothecin. Bioorg. Med. Chem. 2003, 11, 2635-2639.

76. Greenwald, R.; Choe, Y.; Mcguire, J.; Conover, C. Effective drug delivery by PEGylated drug conjugates. Adv. Drug Deliv. Rev. 2003, 55, 217-250.

77. .Greenwald, R.B.; Zhao, H. In Prodrugs: Challenges and Rewards Part I; Stella, V.J.; Borchardt, R.T.; Hageman, M.J.; Oliyai, R.; Maag, H.; Tilley, J.W, Eds.; Springer: New York, 2007; Chapter 2.3.1, pp. 283-337.

78. Franssen, E.; Koiter, J.; Kuipers, C.; Bruins, A.; Moolenaar, F.; Zeeuw ,D.; Kruizinga, W.; Kellog, R.; Meijer, D. Low molecular weight proteins for renal drug targeting. Preparation of Drugprotein conjugates and drug-spacer derivatives and their catabolism in renal cortex homogenates and lysosomal lysates. J. Med. Chem. 1992, 35, 1246-1459.

79. Takakura, Y, Matsumoto, S, Hashida, M, Sezaki, H. Physicochemical Propertiesband Antitumor Activities of Polymeric Prodrugs of Mitomycin C with Different Regeneration Rates. J. Control. Release 1989, 10, 97-105.

80. Gilmer, J.F.; Simplício, A.L.; Clancy, J.C. A new amino-masking group capable of pH-triggered amino-drug release. Eur. J. Pharm. Sci. 2005, 24, 315-323.

81. Gilmer, J.F.; Simplício, A.L.; Clancy, J.C. $\beta$-Aminoketones as prodrugs with pH-controlled activation. Int. J. Pharm. 2007, 336, 208-214.

82. Krause, M.; Rouleau, A.; Stark, H.; Luger, P.; Lipp, R.; Garbarg, M.; Schwartz, J-C.; Schunack, W. Synthesis, X-ray christalography and pharmacokinetics of novel azomethine prodrugs of $R$ - $\alpha$ methylhistamine: highly potent and selective histamine H3-receptor agonists. J. Med. Chem. 1995, 38, 4070-4079. 
83. Krause, M.; Stark, H.; Schunack, W. Azomethine prodrugs of $R$ - $\alpha$-methylhistamine, a highly potent and selective histamine H3-receptor agonist. Curr. Med. Chem. 2001, 8, 1329-1340

84. Stark, H.; Krause, M.; Rouleau, A.; Garbarg, M.; Schwartz, J-C. Schunack, W. Enzyme-catalyzed prodrug approaches for the histamine H3-receptor agonist $R$ - $\alpha$-methylhistamine. Bioorg. Med. Chem. 2001, 9, 191-198.

85. Bundgaard, H.; Johansen, M. Prodrugs as drug delivery systems IV: $N$-mannich bases as potential novel prodrugs for amides, ureides, amines, and other NH-acidic compounds. J. Pharm. Sci. 1980, 69, 44-46.

86. Higuchi T. In Bioreversible Carriers in Drug Design; Roche, E.B., Ed.; Pergamon Press: New York, 1987.

87. Johansen, M.; Bundgaard, H. Pro-drugs as drug delivery systems. XIII. Kinetics of decomposition of $\mathrm{N}$-Mannich bases of salicylamide and assessment of their suitability as possible pro-drugs for amines. Int. J. Pharm. 1980, 7, 119-127.

88. Bundgaard, H.; Lixbüll, U.; Falch, E. Prodrugs as drug delivery systems. 43. O-acyloxymethyl salicylamide $\mathrm{N}$-Mannich bases as double prodrug forms for amines. Int. J. Pharm. 1986, 29, 1928.

89. Bundgaard, H.; Johansen, M. Hydrolysis of $N$-Mannich bases and its consequences for the biological testing of such agents. Int. J. Pharm. 1981, 9, 7-16.

90. Johansen, M.; Bundgaard, H.; Pro-drugs as drug delivery systems. XXIV. N-Mannich bases as bioreversible lipophilic transport forms for ephedrine, phenethylamine and other amines. Arch. Pharm. Chemi. Sci. Ed. 1982, 10, 111-115.

91. Testa, B.; Mayer, J.M. Hydrolysis in Drug and Prodrug metabolism, Chemistry, biochemistry and enzymology; Wiley-VCH: Weinheim, 2003; Chapter 11, pp. 690-695.

92. Sun, C.; Rodriguez, M.; Zeckner, D.; Sachs, B.; Current, W.; Boyer, R.; Paschal, J.; McMillian, C.; Chen, S. Synthesis and evaluation of oxodioxolenylmethyl carbamate prodrugs of pseudomycins. J. Med. Chem. 2001, 44, 2671-2674.

93. Erez, R.; Ebner, S.; Attali, B.; Shabat, D. Chemotherapeutic bone-targeted bisphosphonate prodrugs with hydrolytic mode of activation. Bioorg. Med. Chem. Lett. 2008, 18, 816-820.

94. Prats G.; Rossi V.; Salvatori E.; Mirelis B. Prulifloxacin: a new antibacterial fluoroquinolone Expert Rev. Anti. Infect. Ther. 2006, 4, 27-41.

95. Tougou, K.; Nakamura, A.; Watanabe, S.; Okuyama Y.; Morino, A. Paraoxonase has a major role in the hydrolysis of prulifloxacin (NM441), a prodrug of a new antibacterial agent, Drug. Metab. Dispos. 1998, 26, 355-359.

96. Caldwell, H.; Adams, H.; Jones, R.; Mann, W.; Dittert, L.; Chang, C.; Swintosky J. Enamine prodrugs. J. Pharm. Sci. 1971, 60, 1810-1812.

97. Murakami, T.; Tamauchi, H.; Yamazaki, M.; Kubo, K.; Kamada, A.; Yata, K. Biopharmaceutical study on the oral and rectal administration of enamine prodrugs of amino acid-like $\beta$-lactam antibiotics in rabbits. Chem. Pharm. Bull. 1981, 29, 1986-1997.

98. Dixon, K.; Greenhill, J. A study of the rates of hydrolysis of certain enaminones. J. Chem. Soc. Perkin. Trans. 1I 1974, 2, 164-168.

99. Naringrekar, V.; Stella, V.J. Mechanism of hydrolysis and structure-stability relationship of enaminones as potential prodrugs of model primary amines. J. Pharm. Sci. 1990, 79, 138-146. 
100. Nielsen, N.; Bundgaard, H. Prodrugs as drug delivery systems. 42. 2-Hydroxymethylbenzamides and 2-acyloxymethylbenzamides as potential prodrug forms for amines. Int. J. Pharm. 1986, 29, 9-18.

101. Wang B.; Nicolaou, M.; Liu, S.; Borchardt, R.T. Structural Analysis of a facile lactonization system facilitated by a "trimethyl lock". Bioorg. Chem. 1996, 24, 39-49.

102. Ameberry, K.; Gerstenberger, A.; Borchardt, R.T. Amine prodrugs which utilize hydroxy amide lactonization. II. A potential esterase-sensitive amide prodrug. Pharm. Res. 1991, 8, 455-461.

103. Amsberry, K.; Borchardt, R.T. Amine prodrugs which utilize hydroxy amide lactonization. I. A potential redox-sensitive amide prodrug. Pharm. Res. 1991, 8, 323-330.

104. Nicolaou M.; Yuan, C.; Borchardt, R.T. Phosphate prodrugs for amines utilizing a fast intramolecular hydroxy amide lactonization. J. Org. Chem. 1996, 61, 8636-8641.

105. Wang, B.; Zhang, H.; Wang, W. Chemical feasibility studies of a potential coumarin-based prodrug system. Bioorg. Med. Chem. Lett. 1996, 6, 945-950.

106. Wang, B.; Zhang, H.; Zheng, A.; Wang, W. Coumarin-based prodrugs. Part 3: structural effects on the release kinetics of esterase-sensitive prodrugs for amines. Bioorg. Med. Chem. 1998, 6, 417-426.

107. Liao, Y.; Wang, B.; Substituted coumarins as esterase-sensitive prodrug moieties with improved release rates. Bioorg. Med. Chem. Lett. 1999, 9, 1795-1800.

108. Liao, Y, Hendrata, S.; Bae, S-Y.; Wang W. The effect of phenyl substituents on the release rates of esterase-sensitive coumarin-based prodrugs. Chem. Pharm. Bul. 2000, 48, 1138-1147.

109. Achiles, K. Coumarin derivatives as protease-sensitive prodrugs. Arch. Pharm. 2001, 334, 209215.

110. El-Shorbagi, A. Model for delivery of amines through incorporation into a tetrahydro-2H-1,3,5thiadiazine-2-thione structure. Eur. J. Med. Chem. 1994, 29, 11-15.

111. Aboul-Fadl, T.; El-Shorbagi, A. New prodrug approach for amino acids and amino-acid-like drugs. Eur. J. Med. Chem. 1996, 31, 165-169.

112. Aboul-Fadl, T.; El-Shorbagi, A. New carriers for representative peptides and peptide drugs. Arch. Pharm. 1997, 330, 327-332.

113. Wang, B.; Wang, W.; Zhang, H.; Shan, D.; Smith, T. Coumarin-based prodrugs. 2. Synthesis and bioreversibility studies of an esterase sensitive cyclic prodrug of Dadle, an opioid peptide. Bioorg. Med. Chem. Lett. 1996, 6, 2823-2826.

114. Shan, D.; Nicolaou, M.; Borchardt, R.T.; Wang B. Prodrug strategies based on intramolecular cyclization reactions. J. Pharm. Sci. 1997, 86, 765-767.

115. Pauletti, G.; Gangwar, S.; Wang, B.; Borchardt, R.T. Esterase-sensitive cyclic prodrugs of peptides: evaluation of a phenylpropionic acid promoiety in a model hexapeptide. Pharm. Res. 1997, 14, 11-17.

116. Wang, B.; Gangwar, S.; Pauletti, G.; Siahaan, T.; Borchardt, R.T. Synthesis of a novel esterasesensitive cyclic prodrug system for peptides that utilises a "trimethyl lock"-facilitated lactonization reaction. J. Org. Chem. 1997, 62, 1363-1367.

117. Bundgaard, H.; Joahnsen, M. Pro-drugs as drug delivery systems XX. Oxazolidines as potential pro-drug types for $\beta$-aminoalcohols, aldehydes and ketones. Int. J. Pharm. 1982, 10, 165-175. 
118. Rasmussen, G.; Bundgaard, H.; Prodrugs of peptides 15. 4-imidazolidinone prodrug derivatives of enkephalins to prevent amino-catalyzed peptidase metabolism in plasma and absortive mucosae. Int. J. Pharm. 1991, 76, 113-122.

119. Larsen, S.; Sidenius, M.; Ahkersen, M.; Larsen, C. Kinetics of degradation of 4-imidazolidinone prodrug types obtained from reacting prilocaine with formaldehyde and acetaldehyde. Eur. J. Pharm. Sci. 2003, 20, 233-240.

120. Bak, A.; Fich, M.; Larsen, B.; Frokjaer, S.; Friis, G. $N$-terminal 4-imidazolidinone prodrugs of Leu-enkephalin: synthesis, chemical and enzymatic stability studies. Eur. J. Pharm. Sci. 1999, 7, 317-323.

Samples Availability: Contact the author.

(C) 2008 by MDPI (http://www.mdpi.org). Reproduction is permitted for noncommercial purposes. 